\title{
A Generalized Stochastic Framework for Analyzing Rock Slopes Stability and Designing Reliable Remedial Measures with Limited Investigation Data: Theory and Field Implementation
}

\section{Akshay Kumar}

IIT Kanpur: Indian Institute of Technology Kanpur

Gaurav Tiwari ( $\square$ gauravt@iitk.ac.in )

IIT Kanpur: Indian Institute of Technology Kanpur

\section{Research Article}

Keywords: Rock Slides, Remedial Measures, Deterministic Approach, Target Reliability, Advanced Resampling Reliability

Posted Date: June 7th, 2021

DOl: https://doi.org/10.21203/rs.3.rs-516255/v1

License: (c) (1) This work is licensed under a Creative Commons Attribution 4.0 International License. Read Full License 


\section{A Generalized Stochastic Framework for Analyzing Rock Slopes}

2 Stability and Designing Reliable Remedial Measures with Limited 3 Investigation Data: Theory and Field Implementation

4 Akshay Kumara , Gaurav Tiwari ${ }^{a}$, *

$5 \quad$ a Department of Civil Engineering, IIT Kanpur, Kanpur, Uttar Pradesh 208016, India

$6 \quad *$ Corresponding author; Email: gauravt@iitk.ac.in

\section{Abstract}

8 Availability of limited data for rock properties is a very frequently encountered issue for 9 the rock slopes along Himalayan highways due to problems like high costs, manual efforts, geological complexities, difficult terrain etc. involved in rock testing and investigation. Under these conditions, support estimation for rock slides mitigation using traditional deterministic and reliability approaches becomes highly questionable due to inaccuracy in the estimated statistical parameters of rock properties. To resolve this issue, this article proposes a computationally efficient methodology which utilizes Advanced Re-Sampling Reliability Approach (ARRA) along with deterministic approach and Target Reliability Approach (TRA) to estimate required support for rock slides mitigation when limited field and laboratory investigation data is available, with acceptable accuracy and confidence. Proposed methodology was used to design the support measures to mitigate two massive rock slides along a rock-slide prone highway i.e. Rishikesh-Badrinath National Highway (NH-58) in India. It was observed from the analysis that availability of limited test data induces high uncertainty in the statistical parameters (mean and standard deviation) and probability distribution of rock properties. Support estimation carried out using traditional deterministic and reliability approaches with this inaccurate probabilistic characterization of rock properties, can lead to inaccurate support estimates for potential rock slides in the presence of limited data; however these methods when coupled with ARRA can lead to significant improvement in computational efficiency and the designer's confidence for the estimated support.

Keywords: Rock Slides, Remedial Measures, Deterministic Approach, Target Reliability, Advanced Re-sampling Reliability

\section{Introduction}

Massive rock slides were observed during the construction of civil and military infrastructure development projects recently in the Himalayan regions of India leading to 
significant financial and human lives losses. According to some studies, rock-slides causes an economical loss of $\$ 1.35$ billion along with several human lives for the total $89000 \mathrm{~km}$ of the highways and roads in the mountainous topography of northern India alone, signifying the gravity of situation (Mathur, 1982).Efforts have been made in the past to develop different remedial/support measures like rock bolting, slope flattening etc. to mitigate these rock slides. However, estimation of the required support to prevent rockslides is difficult task due to complex failure mechanisms and associated high uncertainties with rock properties. While the identification of failure mechanism for a rock slide is a trivial issue now a day after the development of kinematic stereographic analysis; second issue related to uncertainties in rock properties is still a non-trivial issue. Different reliability methods like First Order Reliability Method (FORM), Second Order Reliability Method (SORM), Monte-Carlo (MC) simulation etc. have been developed over the years to consider these uncertainties in geotechnical engineering analysis (Ang and Tang, 1984; Baecher and Christian, 2003). Still, the studies on their applicability for stability analysis and design of mitigation measures for rock slides are very limited, possibly due to nonfamiliarity of rock practitioners and mathematical complexities associated with these methods (Duzgun et al., 1995; Mauldon and Ureta, 1996; Tiwari and Latha, 2017; Pandit et al., 2018; Pandit et al., 2019; Tiwari and Latha, 2019).

Further in all these available limited studies, one major issue which is completely ignored is that the accuracy of these traditional reliability methods depends significantly on the accuracy of the estimated statistical parameters (mean, standard deviation (SD) and Probability Distribution (PD))of rock properties, which in turn depend on the quality and quantity of field and laboratory investigation data. Even if the quality of test data is maintained by performing tests according to standard methods suggested by ISRM, quantity (number of test data) of the test data in rock mechanics domain remains inadequate mostly due to involvement of high costs; absence of any strict guidelines regarding numbers; practical difficulties like site preparation, sample collection, sample disturbance, data interpretation etc. involved in lab and in-situ testing (Duzgun et al., 2002; Wyllie and Mah, 2004; Ramamurthy, 2014; Bozorgzadeh and Harrison, 2019). This leads to high uncertainty in the statistical parameters (mean and SD) and PD of these rock properties estimated from this data, thus reducing the accuracy of traditional methods significantly (Luo et al., 2013; Pandit et al., 2019).To the author's best knowledge, very limited efforts have been made in the past to deal with this issue of limited data availability 
while estimating support for rock slides mitigation, while this issue is encountered by rock practitioners very frequently in the field.

This paper deals with this issue by proposing a practical and computationally efficient methodology which can deal with the uncertainty in statistical parameters (mean and SD) and PD of rock properties arising due to availability of limited rock properties data, while estimating support requirements for rock slides mitigation. This method utilises bootstrapping based Advanced Re-Sampling Reliability Approach (ARRA) (Luo et al., 2013; Li et al., 2015a; Pandit et al., 2019) along with traditional deterministic and reliability approaches. Proposed methodology was suggested to design support measures for two potential rock-slides along a rock-slide prone national highway $(\mathrm{NH})$ i.e. Rishikesh-Badrinath (NH-58) highway situated in Uttarakhand state of India. These sites were located close to massive rock-slide location and were showing continuous failures even after providing the support estimated by traditional approaches possibly due to inaccurate probabilistic characterisation of rock properties due to limited data availability. This study describes the advantages of the proposed methodology over traditional methods in the support estimation for rock slides mitigation with limited available test data for rock properties, on the criteria of the accuracy, computational efficiency and rock practitioner's confidence.

\section{Details of the Components of Proposed Methodology}

This section of the paper describes briefly some of the major components involved in the proposed methodology - i) Estimation of uncertainty in rock properties ii)Target Reliability Approach (TRA) iii) Advanced Re-Sampling Reliability Approach (ARRA).

\subsection{Estimation of Uncertainty in Rock Properties}

In this section, statistical parameters i.e. mean, SD and PD of rock properties are estimated using original test data set, which are required for traditional deterministic and reliability analysis. Later, uncertainties in these estimated mean, SD and PD of rock properties arising due to limited data are estimated using bootstrap technique which are required for ARRA. Details are explained as below.

\section{a) Estimation of Uncertainty in Rock properties using Original Data}


Statistical properties i.e. Mean $\left(\bar{X}_{N}\right)$ and SD $\left(S_{N}\right)$ of the rock properties can be estimated from original lab and field test data set $\left(X_{1}, X_{2}, \ldots, X_{n}\right)$, using common statistical methods (Duzgun et al., 2002) as

$$
\bar{X}_{N}=\frac{1}{N} \sum_{i=1}^{N} X_{i} ; \quad S_{N}=\sqrt{\frac{1}{N-1} \sum_{i=1}^{N}\left(X_{i}-\bar{X}_{N}\right)^{2}}
$$

Acceptable probability distributions (PDs) for these rock properties are evaluated by performing goodness-of-fit test i.e. Kolmogorov-Smirnov (KS) and Chi-Square test (Ang and Tang, 1984). Among these acceptable PDs, best PD for a rock property is the one which has minimum Akaike information criterion $\left(A I C_{D}\right)$ i.e.

$$
A I C_{D}=-2\left(\log \left(L_{D}\right)\right)+2 K_{D}
$$

Where $L_{D}=$ maximum likelihood estimator associated with a PD D; $K_{D}=$ number of parameters of candidatePD required to fully characterize the PD D.

\section{b) Estimation of Uncertainty in Mean, SD and PD of Rock Properties due to Limited}

\section{Data Availability}

As mentioned previously, probabilistic characterization of rock properties carried out in the previous section (section 2.1 a) can be inaccurate in the presence of limited test data $(N$ is small) i.e. mean, SD and PD of the rock properties may themselves contain high uncertainties. To quantify these uncertainties, bootstrap technique is used in the present study owing to its simplicity in engineering applications(Most and Knabe, 2010; Luo et al., 2013; Li et al., 2015b; Pandit et al., 2019). Details of bootstrap method are given below.

Let us assume an original sample of input random variable (rock property) $\boldsymbol{X}=$ $\left\{X_{1}, X_{2}, \ldots, X_{N}\right\}$ with mean $\bar{X}_{N}$ and SD $S_{N}$. A bootstrap sample of same size $(N$ sized $) \boldsymbol{B}_{\boldsymbol{i}}=$ $\left\{B_{i, 1}, B_{i, 2}, \ldots, B_{i, N}\right\}$ is generated by repeated random sampling with replacement, from the original data set $\boldsymbol{X}$. Sample size is kept same as that of original sample size to avoid any underestimation or overestimation in sample statistics (Johnson, 2001). There will be associated sample mean, SD and AIC value for a PD, for each bootstrap sample. For each bootstrap sample, every vector $X_{i}$ has an equal probability of being chosen. For every bootstrap sample, statistical parameters of sample i.e. mean $\left(\bar{B}_{i}\right), \operatorname{SD}\left(S_{i}\right)$ are estimated as

$$
\bar{B}_{i}=\frac{1}{N} \sum_{j=1}^{N} B_{i, j} ; \quad S_{i}=\sqrt{\frac{1}{N-1} \sum_{j=1}^{N}\left(B_{i, j}-\bar{B}_{i}\right)^{2}}
$$


126 This procedure is to be repeated to obtain $N_{s}$ bootstrap samples, which are used to obtain

127 corresponding sample means and SDs. Then bootstrap mean $\left(\left[\bar{X}_{N_{S}}\right]_{\text {mean }}\right)$ and bootstrap SD

$128\left(\sigma_{\bar{X}_{N_{S}}}\right)$ of sample mean value can be estimated as

129

$$
\left[\bar{X}_{N_{S}}\right]_{\text {mean }} \approx \frac{1}{N_{S}} \sum_{i=1}^{N_{S}} \bar{B}_{i} ; \quad \sigma_{\bar{X}_{N_{S}}} \approx \sqrt{\frac{1}{N_{S}-1} \sum_{i=1}^{N_{S}}\left(\bar{B}_{i}-\left[\bar{X}_{N_{S}}\right]_{\text {mean }}\right)^{2}}
$$

130

131

Similarly, bootstrap mean $\left(\left[S_{N_{S}}\right]_{\text {mean }}\right)$ and $\mathrm{SD}\left(\sigma_{S_{N_{S}}}\right)$ of sample SD values can be estimated as

$$
\left[S_{N_{s}}\right]_{\text {mean }} \approx \frac{1}{N_{s}} \sum_{i=1}^{N_{S}} S_{i} ; \quad \sigma_{S_{N_{S}}} \approx \sqrt{\frac{1}{N_{S}-1} \sum_{i=1}^{N_{S}}\left(S_{i}-\left[S_{N_{S}}\right]_{\text {mean }}\right)^{2}}
$$

Similarly, uncertainty in the PDs for a rock property can be estimated by estimating the bootstrap statistics i.e. mean $\left(\mu_{A I C_{D}}\right)$ and $\mathrm{SD}\left(\sigma_{A I C_{D}}\right)$ of $A I C_{D}$ (Eq.(2)) of a candidate probability distribution $\mathrm{D}$.

$$
\mu_{A I C_{D}}=\frac{1}{N_{s}} \sum_{i=1}^{N_{S}} A I C_{i_{D}} ; \sigma_{A I C_{D}}=\sqrt{\frac{1}{N_{S}-1} \sum_{i=1}^{N_{S}}\left(A I C_{i_{D}}-\mu_{A I C_{D}}\right)^{2}}
$$

\subsection{Target Reliability Approach (TRA)}

Proposed methodology requires support estimation using traditional reliability approach also. Although lesser known in the rock mechanics domain; Target Reliability Approach (TRA) was used for this purpose due to its significant accuracy and excellent computational efficiency (Basha and Babu, 2010). TRA is basically formulated as the inverse of FORM, in which search is carried for the points whose distances in standard normal $\mathrm{U}$ space from the origin are equal to the target reliability index i.e. $\beta_{\text {target }}$ and among these points, the point selected is the one for which performance function i.e. $G(\boldsymbol{u})$ is minimum. This point is called Minimum Performance Target Point (MPTP) represented as $\boldsymbol{u}$. Figure 1 demonstrates the methodology adopted to search MPTP corresponding to $\beta_{\text {target }}$. TRA can be mathematically expressed as an optimization problem to find $\boldsymbol{u}$ which is:

\section{Minimize: $G(\boldsymbol{u})$}

$$
\text { Subjected to: }\|\boldsymbol{u}\|=\beta_{\text {target }}
$$


151 Using the method of Lagrange multipliers, MPTP $\left(\left[u_{i}\right]_{i=1}^{n}\right)$ in standard normal space for $152 \beta_{\text {target }}$ can be expressed as:

$$
\left[u_{i}\right]_{i=1}^{n}=-\beta_{\text {target }} \frac{\left[\frac{\partial G}{\partial x_{i}} \times \sigma_{X_{i}}\right]_{i=1}^{n}}{\sqrt{\sum_{i=1}^{n}\left\{\frac{\partial G}{\partial x_{i}} \times \sigma_{X_{i}}\right\}^{2}}}
$$

154

155

where $G\left(\boldsymbol{X}_{\boldsymbol{i}}\right)$ is performance function involving 'n' random variables.

The transformations of MPTP between original space $\left[x_{i}\right]_{i=1}^{n}$ and standard normal space $\left[u_{i}\right]_{i=1}^{n}$ is performed as:

$$
x_{i}=\mu_{X_{i}}+\sigma_{X_{i}} \times u_{i}
$$

where, $\mu_{X_{i}}$ and $\sigma_{X_{i}}$ are the mean and SD value of random variable $X_{i}$.

For non-normal input random variables, the Rackwitz and Fiessler (1978) transformation is used in the current study to transform them into equivalent normal variables as shown below:

$$
\begin{gathered}
\sigma_{X_{i}}^{N}=\frac{\phi\left[\Phi^{-1}\left[F_{X_{i}}\left(x_{i}\right)\right]\right]}{f_{X_{i}}\left(x_{i}\right)} \\
\mu_{X_{i}}^{N}=x_{i}-\Phi^{-1}\left[F_{X_{i}}\left(x_{i}\right)\right] \times \sigma_{X_{i}}^{N}
\end{gathered}
$$

Where $\mu_{X_{i}}^{N}$ and $\sigma_{X_{i}}^{N}$ are mean and SD of equivalent normal distribution, $\Phi[$ [.] and $\phi[$.$] are the$ $\mathrm{CDF}$ and the PDF of the standard variate, respectively, and $F_{X_{i}}($.$) and f_{X_{i}}($.$) are the CDF$ and PDF of the original non-normal random variable.

\subsection{Advanced Re-Sampling Reliability Approach (ARRA)}

Advanced Re-Sampling Reliability Analysis (ARAA) is basically a reliability technique which can consider the uncertainty in the statistical parameters (mean and SD) and PD of input random variables (rock properties) in the analysis (Pandit et al., 2019). Process adopted to perform ARAA can be summarized as: Initial step for ARRA is to obtain a bootstrap sample and to estimate its sample mean and SD values (section 2.1). Second step is to evaluate best PD having lowest $A I C_{D}$ value among the acceptable candidate PDs for this bootstrap sample (Section 2.1 a). Third step would be to perform Monte-Carlo (MC) simulations on the performance function to obtain its mean, SD and PD using estimated sample mean, SD and PD for each bootstrap sample. Fourth step is to evaluate corresponding reliability index $(\beta)$ using mean, SD and PD of performance function for this bootstrap sample. This whole process is then repeated for $N_{S}$ number of bootstrap 
samples to obtain $N_{S}$ values and hence, the distribution of reliability index $(\beta)$ from which further interpretations can be made.

\section{Proposed Methodology for Support Design to Mitigate Rock Slides}

This section describes the systematic steps involved in the support estimation for rock slides mitigation using proposed methodology. Figure 2 shows the detailed flowchart of the proposed methodology. Following section briefly outlines the steps to be followed in the proposed methodology.

Step 1 Derivation of Performance Function: Derive the performance function i.e. Factor of Safety (FOS) for this study, as a function of the relevant input rock properties, external forces and support force i.e.

$$
G(\boldsymbol{x}, \boldsymbol{y}, T)=F O S(\boldsymbol{x}, \boldsymbol{y}, T)-1
$$

Where $\boldsymbol{x}, \boldsymbol{y}=$ Vector of random rock properties and random external forces; $\mathrm{T}=$ Support force.

Step 2 Estimation of Rock Properties: Estimate the input rock properties from standard International Society of Rock Mechanics (ISRM) suggested field and laboratory testing methods to generate the original data set for these rock properties.

Step 3Estimation of Uncertainty in Rock Properties: Estimate statistical parameters (mean and SD) and probability distribution (PD) from the original data set of these rock properties (section 2.1 a). Further, characterize uncertainty in the mean, SD and PD of these rock properties by carrying out Bootstrap Modeling (Section $2.1 \mathrm{~b}$ ).

Step 4 Evaluation of Potential Rock Slide Stability under In-Situ Condition: Evaluate the stability of potential rock slide under in-situ condition without any external support (Putting $\mathrm{T}=0$ in Eq.(12)) using deterministic, traditional reliability and ARRA to ascertain, if any support is required to stabilize the slope. Deterministic analysis is carried out to estimate FOS by simply putting mean values of geometrical dimensions of slope, rock properties and external forces in the performance function (Eq. (12)). Traditional reliability analysis is carried out by estimating random values of FOS for random realisations of input random variables i.e. rock properties and external forces by performing Monte-Carlo simulation (MCs) on performance function i.e. $G(\boldsymbol{x}, \boldsymbol{y}, T=0)$. Reliability index $(\beta)$ can be estimated using mean of FOS $\left(\mu_{F O S}\right)$ and SD of FOS $\left(\sigma_{F O S}\right)$ as given below

$$
\beta=\frac{\mu_{F O S}-1}{\sigma_{F O S}}
$$


212 For ARRA, distribution of $\beta$ can be estimated as explained in section 2.3. Support is required when the evaluated FOS, $\beta$ and distribution of $\beta$ from these approaches are not meeting corresponding acceptability criteria.

Multiple acceptability criteria corresponding to different approaches are considered due to involvement of significant risk with this project and massive failures observed in the past. Acceptability criteria adopted in this study is based on the extensive literature review and can be summarized as:

a) For deterministic analysis, FOS $\geq 1.5$ (Wyllie and Mah, 2004)

b) For traditional reliability analysis, $\beta \geq 2.0$ (Chowdhury and Flentje, 2003; Diamantidis et al., 2006)

c) For ARRA, area under PD curve of reliability index $(\beta)$ for $\beta<2.0$ i.e. $P_{A B \beta_{t}}$ should not exceed 0.01(1\%). Acceptability criterion for ARRA is based on the probability interpretation provided by Cai (2011) and Lichtenstein and Newman (1967) - When a probability is translated into a verbal description of uncertainty, $1 \%$ is equivalent to virtually impossible.

Step 5 Support Estimation for Rock Slide Mitigation: This step is to estimate support requirements for the potential rock slides, if they are not meeting the acceptability criteria under in-situ condition. Basic idea is to estimate the support required, satisfying all the above mentioned criteria separately and maximum among them is referred as the final required support. Another important point to notice is that this step is designed to minimize the computational efforts by appropriately guessing the initial support force trial in TRA and ARRA by performing the analysis in a systematic sequence. This step is clearly described in Fig. 2, however brief description of the logic behind this step is summarized here.

Computational efforts involved in the support estimation approaches can be arranged in the increasing order as: deterministic, TRA and ARRA. While, TRA and ARRA require initial support force trial value to initiate the calculation for support estimation, there is no such issue in deterministic analysis. Hence, support is estimated by simplest and most popular approach i.e. deterministic approach initially by using mean values of - rock properties, external forces; pre-decided value of required FOS (1.5 for this study) in Eq.(12), to get the required support force i.e. $\mathrm{T}_{\mathrm{DET}}$. $\mathrm{T}_{\mathrm{DET}}$ will satisfy first acceptability criterion i.e. FOS $\geq 1.5$. For the support estimation using TRA, major issue is regarding the assumption of initial trial support force value i.e. $T_{T R A}^{\text {trial } 1}$. In this study, this issue is resolved by simply 
assuming $T_{T R A}^{\text {trial } 1}=\mathrm{T}_{\mathrm{DET}}$. This assumption leads to significant reduction in the number of iterations and hence, the involved computational effort in TRA. After several iterations, final support force value corresponding to $\beta=2$ is estimated through TRA which is represented as $\mathrm{T}_{\mathrm{TRA}}$ (Section 2.2). $\mathrm{T}_{\mathrm{TRA}}$ will satisfy first and second acceptability criteria i.e. $\mathrm{FOS} \geq 1.5$ and $\beta \geq 2.0$.

Most important part is to estimate support requirements for the rock slides mitigation using ARRA. Support estimation by ARRA is carried out by estimating distributions of $\beta$ as explained in section 2.3 for different values of support force trials $(T)$ in $G(\boldsymbol{x}, \boldsymbol{y}, T)$, till acceptability criterion of $P_{A B \beta_{t}}$ not exceeding $0.01(1 \%)$ is met. For $n$ trials of support force, total number of slope stability analysis models required to be evaluated will be $n \times$ $10^{8}\left(1\right.$ bootstrap analysis $=10^{4} \mathrm{MC}$ simulations; $10^{4}$ bootstrap analysis $=10^{8} \mathrm{MC}$ simulations). Only way to reduce this computational effort is to reduce these support force trials i.e. $n$, which is possible through an appropriate guess for initial support force trial for ARRA i.e. $T_{A R R A}^{\text {trial } 1}$.For this study, this is done by considering $T_{A R R A}^{\text {trial } 1}=\max \left(\mathrm{T}_{\mathrm{DET}}, \mathrm{T}_{\mathrm{TRA}}\right)$ which helped in reducing computational efforts significantly, which could otherwise be huge for any random guess of $T_{A R R A}^{\text {trial } 1}$. $\mathrm{T}_{\text {ARRA }}$ will satisfy all acceptability criteria i.e. FOS $\geq 1.5, \beta \geq 2.0$ and $P_{A B \beta_{t}} \leq 1 \%$ which is the final support i.e. $\mathrm{T}_{\text {Final. }}$

It is clear that present methodology provides three major advantages: 1) It can consider the uncertainty in statistical parameters of rock properties explicitly leading to accurate support estimation in the presence of limited data 2) Highly computationally efficient 3) Rock Practitioner will remain highly confident about the support design even in the presence of limited data, since all the popularly adopted acceptability criteria will automatically get satisfied. This is because the final adopted support ( $\left.\mathrm{T}_{\text {Final }}\right)$ inherently satisfies $\max \left(\mathrm{T}_{\mathrm{DET}}, \mathrm{T}_{\mathrm{TRA}}, \mathrm{T}_{\mathrm{ARRA}}\right)$. Final support force i.e. $\mathrm{T}_{\text {Final }}$ can then be distributed along the slopes using the rock bolts and anchors. All the relevant codes are written in MATLAB and are used for support estimation for the rock slides discussed in the next section. These codes can be provided to interested readers working in this field.

\section{Field Application of the Proposed Methodology}

Proposed methodology was used to design support measures for two potential rock-slides with different probable failure mechanisms along an important highway i.e. RishikeshBadrinath highway situated in rock-slide prone Himalayan region of Uttarakhand, India. 
importance due to high pilgrimage and tourism activities and is important for socioeconomic development of the region. From several decades, frequent mass movement phenomena has been observed along this highway due to weak geological formation, steep slopes, highly dissected topography, seismically active area and high rainfall, causing the major hindrance to ongoing traffic (Sarkar et al., 2005; Kanungo et al., 2013; Shukla et al., 2014). Efforts have been made by various researchers to assess the stability of slopes along this highway using landslide hazard zonation maps and providing required support measures for unstable slopes (Kanungo et al., 2013; Sarkar et al., 2018). However, massive rock-slides were observed very recently along some locations of the highway as shown in Fig. 4.

\subsection{Rock-Slide 1}

To identify the expected failure mechanism of this rock slide, kinematic analysis was carried out (Pain, 2012). Expected failure mechanism for this potential rock-slide is planar failure i.e. sliding of rock block along a pre-defined discontinuity plane. Major rock type present at the site is Quartzite with unit weight of rock $(\gamma)=26 \mathrm{kN} / \mathrm{m}^{3}$. Geometrical dimensions of the slope are considered deterministic in all approaches with values given in Table 1. Figure 5 shows the relevant dimensions provided in Table 1. Support design for this potential rock slide is carried out as described in flowchart of Fig. 2 and section 3.

\subsubsection{Derivation of Performance Function}

Performance function for this rock slide was derived analytically using Limit Equilibrium Method (LEM). However, unlike most of the previous studies, non-linearity in shear strength of critical discontinuity is taken into consideration by using Barton-Bandis strength criterion for discontinuity strength. This criterion is based on parameters like Joint Roughness Coefficient (JRC), Joint wall Compressive Strength (JCS) and residual friction angle $\left(\phi_{\mathrm{r}}\right)$ (Barton and Bandis, 1990). Figure 5 shows a potential rock slide with possibility of planar failure and forces acting on this failing rock block. OABC is the sliding block of the rock which is sliding along discontinuity OC. The horizontal force due to water pressure in the tension crack is $U_{1}$, and the uplift force due to water pressure along the critical failure/discontinuity plane is $U_{2}$. An external stabilising bolt force $T$ is applied normal to the slope face OA, which will be inclined at an angle $\alpha$ to the failure plane OC. By force equilibrium in direction normal (n) and parallel (s) to joint plane i.e. $\sum F_{n}=$ $0 \& \sum F_{S}=0$, the general expression for the factor of safety of the rock slope is evaluated as: 


$$
F O S=\frac{F_{\text {resisting }}}{F_{\text {driving }}}=\frac{\sigma_{n} \times \tan \left[\phi_{r}+J R C_{n} \times \log \left(\frac{J C S_{n}}{\sigma_{n}}\right)\right]}{\tau_{s}}
$$

where, normal stress $\left(\sigma_{n}\right)$ can be expressed as:

$$
\sigma_{n}=\frac{W\left\{\left(1-\alpha_{v}\right) \cos \left(\theta_{p}\right)-\alpha_{h} \sin \left(\theta_{p}\right)\right\}-U_{1} \sin \left(\theta_{p}\right)-U_{2}+T \cos (\alpha)}{(H-Z) \operatorname{cosec}\left(\theta_{p}\right)}
$$

where, driving shear stress $\left(\tau_{s}\right)$ can be expressed as:

$$
\tau_{s}=\frac{W\left\{\left(1-\alpha_{v}\right) \sin \left(\theta_{p}\right)+\alpha_{h} \cos \left(\theta_{p}\right)\right\}+U_{1} \cos \left(\theta_{p}\right)-T \sin (\alpha)}{(H-Z) \operatorname{cosec}\left(\theta_{p}\right)}
$$

where, weight of sliding block OABC can be expressed in term of unit weight of rock $(\gamma)$ and slope geometrical parameters shown in Fig. 5 as:

$$
W=\frac{1}{2} \gamma H^{2} \times\left[\left\{1-\left(\frac{Z}{H}\right)^{2}\right\} \cot \left(\theta_{p}\right)-\cot \left(\theta_{f}\right)\right]
$$

Water pressure along tension crack $\left(U_{1}\right)$ and along rock discontinuity $\left(U_{2}\right)$ can be expressed in terms of unit weight of water $\left(\gamma_{w}\right)$ and slope dimensions as:

$$
U_{1}=\frac{1}{2} \gamma_{w} Z_{w}^{2} ; \quad U_{2}=\frac{1}{2} \gamma_{w} Z_{w} \times(H-Z) \operatorname{cosec}\left(\theta_{p}\right)
$$

Where $Z=$ Depth of tension crack; $Z_{w}=$ Depth of water inside tension crack; $\alpha_{h}, \alpha_{v}=$ Horizontal and vertical seismic coefficients.

\subsubsection{Estimation of Rock Properties}

Required rock properties i.e. properties for critical discontinuity (for this case) were estimated using ISRM suggested standard methods. Laboratory scale JCS $\left(J C S_{0}\right)$ values along the discontinuity wall were estimated using N-type Schmidt Rebound Hammer Test (Aydin, 2009) which were later converted to L-type Schmidt Rebound values (Aydin and Basu, 2005). Laboratory Scale JRC $\left(J R C_{0}\right)$ values were estimated by comparing joint profiles with the standard roughness profiles suggested by Barton and Choubey (1977). Once $J R C_{0}$ and $J C S_{0}$ are estimated for laboratory scale sample of length $\left(L_{0}\right)$, corrections are applied to get $J R C_{n}$ and $J C S_{n}$ for in-situ block size $\left(L_{n}\right)$ using following relations:

$$
J R C_{n}=J R C_{0}\left(\frac{L_{n}}{L_{0}}\right)^{-0.02 J R C_{0}} ; J C S_{n}=J C S_{0}\left(\frac{L_{n}}{L_{0}}\right)^{-0.03 J R C_{0}}
$$

Residual friction angle $\left(\phi_{\mathrm{r}}\right)$ was estimated by first carrying out direct shear test on planar fresh discontinuity to get basic friction angle $\left(\phi_{\mathrm{b}}\right)$ and then converting it to $\phi_{\mathrm{r}}$ using Schmidt rebound values for fresh $(R)$ and weathered discontinuity surfaces $(r)$ based correction given as

$$
\phi_{\mathrm{r}}=\left(\phi_{\mathrm{b}}-20\right)+20(r / R)
$$


339 Table 2 summarises the original data set for $J R C_{n}, J C S_{n}$ and residual friction angle $\left(\phi_{\mathrm{r}}\right)$ 340 estimated for the critical discontinuity.

\section{4.1.3.Estimation of Uncertainty in Rock Properties}

\section{a) Estimation of Uncertainty in Rock Properties using Original Data}

Table 3 shows the summary of the estimated mean, SD and best PD of $J C S_{n}, J R C_{n}$ and $\phi_{\mathrm{r}}$ from the original data provided in Table 2 as suggested in section 2.1a.

b) Estimation of Uncertainty in Mean, SD and PD of Rock Properties due to Limited

\section{Data Availability}

347 Uncertainty in mean, SD and PD for these discontinuity properties i.e. $J C S_{n}, J R C_{n}$ and $\phi_{\mathrm{r}}$ is estimated by performing bootstrap analysis (section 2.1b). A total of 10,000 number of bootstrap analysis $\left(N_{S}\right)$ is carried out to get the converged results. Figure 6 shows PDs of the sample mean and sample SD of $J C S_{n}, J R C_{n}$ and $\phi_{\mathrm{r}}$. Table 4 shows the statistical parameters i.e. bootstrap mean and bootstrap SD of sample mean and sample SD. It can be observed that bootstrap mean of the sample mean and sample SD are close to the sample mean and sample SD of all discontinuity properties estimated from the original data set (Table 3). However, there is bootstrap SD associated with sample mean and sample SD which shows that significant uncertainty in the estimated statistical parameters (mean and SD) exists when limited original test data is available. For this rock slide, uncertainty associated with statistical parameters of $J C S_{n}$ is highest and $J R C_{n}$ is lowest. Uncertainty in PDs of $J C S_{n}, J R C_{n}$ and $\phi_{\mathrm{r}}$ are also estimated by generating 10,000 values of $A I C_{D}$ values for each candidate PD. Candidate PDs for these properties are decided on the basis of literature (Duzgun and Bhasin, 2009) and goodness of fit test results. Candidate PDs for $J C S_{n}$ are Normal, Lognormal, Weibull and Gamma; $J R C_{n}$ are Normal, Lognormal, Weibull and Uniform; $\phi_{\mathrm{r}}$ are Normal, Lognormal, Weibull and Gamma. Figure 7 shows the PDs of $A I C_{D}$ values associated with candidate PDs for $J C S_{n}, J R C_{n}$ and $\phi_{\mathrm{r}}$ after kernel density smoothing. Bootstrap mean and SD of $A I C_{D}$ values are provided in Table 5. It can be observed that Bootstrap SD for $A I C_{D}$ is significant which shows the associated high uncertainty in the estimated PDs of discontinuity properties when limited data is available. For this case study, it was observed that bootstrap SD was highest for $J C S_{n}$ and lowest for $J R C_{n}$ values showing that uncertainty associated with PDs of $J C S_{n}$ is highest.

Further, probability of best fit distribution of a particular PD was also evaluated by taking 
total number of bootstrap samples i.e. $N_{s}=10000$ for this case (Table 6). For $J R C_{n}$,

373 Uniform distribution is found to be best-fit PDF with $94.43 \%$ probability. For $J C S_{n}$, Lognormal distribution is found to be best-fit PDF with $65.89 \%$ probability. Lognormal distribution has high probability of being best-fit PDF for $\phi_{\mathrm{r}}$, with $41.34 \%$ probability. Most likely probability distribution for $\phi_{\mathrm{r}}$ is different from the best fit probability distribution evaluated from original data set which was Gamma distribution. This shows that significant inaccuracy exists regarding the evaluation of best fit probability distribution for a random variable (discontinuity property) in the presence of limited test data which can lead to inaccurate estimation of reliability index in traditional reliability analysis which is based on PD evaluated using original data set.

\subsubsection{Evaluation of Potential Rock Slide Stability under In-Situ Condition}

Stability analysis of this potential rock slide is carried out using different approaches under in-situ condition without any support $(T=0)$ to ascertain the requirement of support for rock slide mitigation. Table 3 shows the statistical parameters and PD of the critical discontinuity property along with that of external seismic force (IS:1893, 2002) and depth of water in tension crack. PD of $\alpha_{h}$ and depth of water in the tension crack $\left(Z_{w}\right)$ was assumed to follow exponential distribution (Ahmadabadi and Poisel, 2016).

Deterministic analysis is carried out to estimate FOS by using mean values of geometrical dimensions of slope, rock properties and external forces (Table 1 and Table 3) in derived expression of performance function (Eqs. (14)-(18)). Traditional reliability analysis is carried out by estimating 10,000 values of FOS for 10,000 random realisations of rock properties and external forces based on their statistical parameters and PDs (Table 3) using Monte-Carlo simulation (MCs). Reliability index $(\beta)$ can be estimated using mean of FOS $\left(\mu_{F O S}\right)$ and SD of FOS $\left(\sigma_{F O S}\right)$ using Eq. (13). Advanced Re-Sampling Reliability Analysis (ARRA) is carried out by generating 10,000 bootstrap samples of rock properties i.e. $J C S_{n}$, $J R C_{n}$ and $\phi_{\mathrm{r}}$ from original data given in Table 2. For each bootstrap sample, reliability analysis is carried out by performing 10,000 MCs similar to traditional reliability analysis using Eqs. (14)-(18). For each bootstrap sample, effect of water pressure and seismic 400 forces is considered similar to the traditional reliability analysis. This process is repeated for 10,000 bootstrap samples giving 10,000 values of $\beta$ through which the PD of $\beta$ can be evaluated.

403 Factor of Safety (FOS) estimated from the deterministic analysis is 1.12. Distribution of 404 the FOS obtained from traditional reliability analysis is shown in Fig. 8 and corresponding 
reliability index is 0.61. For ARRA, Table 7 and Fig. 9 provide the details of the distribution of statistical parameters of FOS and reliability index $(\beta)$ for in-situ unreinforced case. It can be observed from Fig. 9 that estimated area under PD curve of $\beta$ for $\beta$ less than 2 i.e. $P_{A B \beta_{t}}$ is approximately $100 \%$ i.e. much higher than acceptable value of $1 \%$. It can be seen that slope under in-situ conditions does not meet any of the acceptability criteria mentioned in step 4 of section 3 , hence requires external support for stabilization.

\subsubsection{Support Estimation for Rock Slide Mitigation}

Initially, support is estimated by deterministic approach using derived performance function in section 4.1.1 with mean values of rock properties and external forces (Table 3) as explained in step 5 (section 3). Required support force estimated using deterministic approach corresponding to the target FOS of 1.5 (T⿰ET) is $2951 \mathrm{kN}$. However, this support was not enough to fulfill the acceptability criteria for traditional reliability analysis as the estimated $\beta$ was found to be 1.77 much lesser than 2.0. Hence, support force was revised using TRA as described in section 2.2 with initial support force trial value i.e. $T_{T R A}^{\text {trial } 1}=$ $T_{D E T}=2951 \mathrm{kN}$. After several iterations required, summarized in Table 8, support force to fulfill the acceptability criterion of $\beta=2.0$ i.e. TTRA was found to be $3640 \mathrm{kN}$.

Support estimation is then carried out using ARRA as explained in step 5 of section 3 with initial support force trail i.e. $T_{A R R A}^{\text {trial } 1}=\max \left(T_{\mathrm{DET}}, \mathrm{T}_{\mathrm{TRA}}\right)=\max (2951,3640)=3640 \mathrm{kN}$. For this initial trial support force, area under PD curve of $\beta$ for $\beta<2$ i.e. $P_{A B \beta_{t}}$ was estimated as approximately 0.50 (50\%) which was considerably lower than unsupported slope (Fig. 10). Still the value of $P_{A B \beta_{t}}$ was much higher than the acceptable value of 0.01 (1\%). Hence, trials were made with increased support force and the support force required to fulfill the acceptability criterion i.e. $P_{A B \beta_{t}}<1 \%$ was found to be $4520 \mathrm{kN}$ (Fig. 10). Table 7 also shows the significant improvement in confidence interval (CI) of the $\beta$ for the slope supported with $\mathrm{T}_{\text {Final }}=4520 \mathrm{kN}$ as compared to slope under in-situ condition.

It is suggested to distribute this support force along the slope face using $32 \mathrm{~mm}$ diameter rock bolts of $100 \mathrm{kN}$ tensile capacity with c/c vertical spacing of $4 \mathrm{~m}$ as shown in Fig. 11 . All the rock bolts should be pre-tensioned to the $80 \%$ of their tensile capacity to restrain any movement of the rock blocks along the critical discontinuity. Rocks bolts are suggested to be installed in the $100 \mathrm{~mm}$ diameter boreholes drilled perpendicular to the slope face with the trend of $\pm 180^{\circ}$ with minimum grout cover of $25 \mathrm{~mm}$ placed between rock and bolts. Further, to ensure long life of the rock bolts, the rock bolts were applied 
with corrosion inhibitor solution. Additionally, to mitigate any shallow slides, a shotcrete cover of $100 \mathrm{~mm}$ in two layers of $50 \mathrm{~mm}$ each is suggested to be applied.

\subsection{Rock Slide 2}

Similar to the rock slide 1 , kinematic analysis was carried out for this potential rock slide and it was observed that the possible failure mechanism for this potential rock slide is wedge failure (Pain, 2012). The major rock type present at the site is Dolomite (unit weight $\gamma=25 \mathrm{kN} / \mathrm{m}^{3}$ ). Geometrical dimensions of this potential rock slide are given in Table 9 and Fig. 12 shows the pictorial representation of these dimensions. Support design for this potential rock slide is carried out as described in Fig. 2 and section 3. This case study is explained briefly due to length limitation of the paper and hence only important results are provided. However, more details for this case study can be provided to the interested readers.

\subsubsection{Derivation of Performance Function}

Performance function for this rock slide was also derived analytically using Limit Equilibrium Method (LEM). Let us assume a potential rock slide showing the possibility of wedge failure and forces acting on the failing rock block as shown in Fig. 12. Force equilibrium in the directions of $s, n$ and $t$ i.e. $\sum F_{s}=0, \sum F_{n}=0$ and $\sum F_{t}=0$ are considered and the general expression for the FOS of the rock slope against wedge failure is evaluated as given in Eqs. (21)-(22) below.

FOS

$=\frac{N_{1} \tan \left[\phi_{r 1}+J R C_{n 1} \times \log \left(\frac{J C S_{n 1} \times A_{1}}{N_{1}}\right)\right]+N_{2} \tan \left[\phi_{r 2}+J R C_{n 2} \times \log \left(\frac{J C S_{n 2} \times A_{2}}{N_{2}}\right)\right]}{W\left(\left(1-\alpha_{v}\right) \sin D_{i}+\alpha_{h} \cos D_{i}\right)-T \sin \alpha}$

Where $N_{1}$ and $N_{2}$ are the normal forces acting normal to the critical discontinuities 1 and 2, $J R C_{n 1}$ and $J R C_{n 2}$ are Joint Roughness Coefficient values for critical discontinuities 1 and $2, J C S_{n 1}$ and $J C S_{n 2}$ are Joint wall Compressive Strength values for critical discontinuities 1 and $2, \phi_{r 1}$ and $\phi_{r 2}$ are residual friction angle values for critical discontinuities 1 and 2 , $A_{1}$ and $A_{2}$ are sliding planes area for discontinuities 1 and 2 , and $D_{i}$ is dip of intersection line of discontinuities 1 and 2 .

And also,

$$
U_{1}=\frac{1}{6} \gamma_{w} Z_{i} \times A_{1} ; U_{2}=\frac{1}{6} \gamma_{w} Z_{i} \times A_{2}
$$

The uplift forces due to water pressure along discontinuity plane 1 and 2 are $U_{1}$ and $U_{2}$, respectively. An external stabilising bolt force $T$ is inclined at an angle $\alpha$ to normal along the intersection line. $Z_{i}$ is the vertical depth of water along intersection line. 
471 Table 10 summarises the original test data set for $J C S_{n}, J R C_{n}$ and $\phi_{\mathrm{r}}$ for both critical discontinuities estimated using similar methodology as explained in section 4.1.2.

\subsubsection{Estimation of Uncertainty in Rock Properties}

Table 11 summarizes the statistical parameters of the discontinuity properties estimated from the original data set similar to the previous case study (section 4.1.3 a).

476 Further, it was observed that significant uncertainty exists in statistical parameters of rock 477 properties in the presence of limited test data as shown in Fig. 13. Estimation of this uncertainty is carried out in a similar way as previous case study described in section 4.1.3.

\subsubsection{Evaluation of Potential Rock Slide Stability under In-Situ Condition}

Analysis for unsupported slope is carried out in a similar manner as that of previous case study using performance function derived in section 4.2.1. FOS estimated by deterministic analysis was 1.11 . Reliability index $(\beta)$ estimated by traditional reliability was 0.41 . For ARRA, Fig. 14 shows the distribution of $\beta$ and Table 12 summarises the result for CI of $\beta$ under unsupported in-situ condition. It is clear that slope does not meet any defined acceptability criteria under in-situ condition.

\subsubsection{Support Estimation for Rock Slide Mitigation}

487

Support is estimated for this case study in the similar manner as explained for previous case study using performance function derived in section 4.2.1. Magnitude of estimated $\mathrm{T}_{\mathrm{DET}}$ and $\mathrm{T}_{\mathrm{TRA}}$ are $17,255 \mathrm{kN}$ and $23,300 \mathrm{kN}$ respectively. For ARRA, initial trial i.e.

$T_{A R R A}^{\text {trial } 1}$ is considered as $\max \left(\mathrm{T}_{\mathrm{DET}}, \mathrm{T}_{\mathrm{TRA}}\right)$ which is $23,300 \mathrm{kN}$. Final value of the required support force i.e. $\mathrm{T}_{\mathrm{ARRA}}=\mathrm{T}_{\text {Final }}$ was $25,200 \mathrm{kN}$ estimated after several trials. Figure 14 and Table 12 shows the significant improvement in the PD and CI of $\beta$ for supported slope as compared to unsupported slope under in-situ condition. Figure 15 shows the remedial design suggested to mitigate this rock slide in the field similar to the previous rock slide case.

\section{Summary and Concluding Remarks}

497 This paper proposes an advanced reliability based methodology to design accurate support measures for mitigation of potential rock slides along Indian Himalayan highways in the presence of uncertain rock properties with limited test (investigation) data. Proposed methodology is based on advanced re-sampling reliability analysis (ARRA) which couples inverse reliability and traditional deterministic approaches to achieve the better computational efficiency and accuracy. Proposed methodology was demonstrated for the 
503 support design of two potential rock slides along the Rishikesh - Badrinath highway.

504 Significant uncertainties (COV of 50\%) were estimated in the statistical parameters of rock 505 properties, which restricted the usage of deterministic and inverse reliability approaches. It 506 was concluded that uncertainties in input parameter (rock properties) distribution type and 507 its parameters significantly affect the reliability index and the estimated support for rock 508 slopes. Further, rock designers can remain more confident and informed about the designed 509 support measures using proposed methodology, since the results are obtained as the 510 reliability index interval instead of a fixed value and also the estimated support meets all 511 the acceptability criteria. For the considered case studies, reliability index intervals were 512 improved to [1.9887, 2.4209] and [1.9999, 2.2524] for the supported slopes, as compared 513 to [0.3518, 0.8341] and [0.2840, 0.5233] respectively for natural slopes, corresponding to 514 the confidence interval of $0.5-99.5 \%$.

515 There are some limitations and important points to note regarding the present study. In the 516 present study, case studies considered are of structurally-controlled rock slides; however, 517 support estimate for stress-controlled circular rock-slides can also be made similarly. 518 Support estimates for rock-slides mitigation by the proposed methodology highly depends 519 on the adopted "acceptability criteria". Acceptability criteria will depend on the 520 practitioner's confidence on the data and importance of the project. This methodology is 521 efficient when the data available for a rock property is small $(<30)$. For large number of 522 samples, traditional approaches will be sufficiently accurate. Proposed methodology does 523 not consider observational and transformational uncertainties associated with the 524 estimation of different rock properties. They can be considered in future studies.

Acknowledgements

527 Authors would like to acknowledge Dr. Anindya Pain and Dr. Mahesh Sharma, Scientist, 528 CBRI, India to provide important field and laboratory investigation results and pictures of 529 the site.

530

\section{Conflict of Interest}

532 The authors declare that they have no conflict of interest. 
533

534

535

536

537

538

539

540

541

542

543

544

545

546

547

548

549

550

551

552

553

554

555

556

557

558

559

560

561

562

563

564

565

566

\section{References}

Ahmadabadi M, Poisel R (2016) Probabilistic analysis of rock slopes involving correlated nonnormal variables using point estimate methods. Rock Mechanics and Rock Engineering 49(3):909-925

Ang AHS, Tang WH (1984) Probability concepts in engineering planning and design. Wiley, New York

Aydin A (2009) ISRM Suggested method for determination of the Schmidt hammer rebound hardness: Revised version. International Journal of Rock Mechanics and Mining Sciences 46:627-634

Aydin A, Basu A (2005) The Schmidt hammer in rock material characterization. Engineering Geology 81(1):1-4

Baecher GB, Christian JT (2003) Reliability and statistics in geotechnical engineering. John Wiley and Sons

Barton N, Bandis S (1990) Review of predictive capabilities of JRC-JCS model in engineering practice. In Rock Joints, Proc int symp on rock joints, Loen, Norway

Barton N, Choubey V (1997) The shear strength of rock joints in theory and practice. Rock Mechanics 10(1-2):1-54

Basha BM, Babu GS (2010) Optimum design for external seismic stability of geosynthetic reinforced soil walls: reliability based approach. Journal of geotechnical and geoenvironmental engineering 136(6):797-812

Bozorgzadeh N, Harrison JP (2019)Reliability-based design in rock engineering: Application of Bayesian regression methods to rock strength data. Journal of Rock Mechanics and Geotechnical Engineering 11(3):612-27

Cai M (2011)Rock mass characterization and rock property variability considerations for tunnel and cavern design. Rock Mechanics and Rock Engineering 44(4):379-99

Chowdhury R, Flentje P (2003) Role of slope reliability analysis in landslide risk management. Bulletin of Engineering Geology and the Environment 62(1):41-46

Diamantidis D, Duzgun S, Nadim F, Wohrle M (2006) On the Acceptable Risk for Structures Subjected to Geohazards. Proceedings of ECI Conference: Geohazards-Technical, Economical and Social Risk Evaluation Norway

Duzgun HSB, Bhasin RK (2009) Probabilistic stability evaluation of Oppstadhornet rock slope Norway. Rock Mechanics and Rock Engineering 42(5):729-749

Duzgun HSB, Pasamehmetoglu AG, Yucemen MS (1995) Plane failure analysis of rock slopes: A reliability approach. International Journal of Surface Mining and Reclamation 9(1):1-6 
Duzgun HSB, Yucemen MS, Karpuz CA (2002) A probabilistic model for the assessment of uncertainties in the shear strength of rock discontinuities. International Journal of Rock Mechanics and Mining Sciences 39(6):743-54

IS1893 (2002) Criteria for earthquake resistant design of structures. Indian Standard Code by Bureau of Indian Standards, New Delhi

Johnson RW (2001) An introduction to the bootstrap. Teaching Statistics23(2):49-54

Kanungo DP, Pain A, Sharma S (2013) Finite element modeling approach to assess the stability of debris and rock slopes: a case study from the Indian Himalayas. Natural Hazards 69(1):1-24

Li DQ, Jiang SH, Cao ZJ, Zhou CB, Li XY, Zhang LM (2015a) Efficient 3-D reliability analysis of the $530 \mathrm{~m}$ high abutment slope at Jinping I Hydropower Station during construction. Engineering Geology 195:269-81

Li DQ, Tang XS, Phoon KK (2015b) Bootstrap method for characterizing the effect of uncertainty in shear strength parameters on slope reliability. Reliability Engineering \& System Safety 140:99-106

Lichtenstein S, Newman JR (1967) Empirical scaling of common verbal phrases associated with numerical probabilities. Psychonomic Science 9(10):563-564

Luo Z, Atamturktur S, Juang CH (2013) Bootstrapping for characterizing the effect of uncertainty in sample statistics for braced excavations. Journal of geotechnical and geoenvironmental engineering 139(1):13-23

Mathur HN (1982) Influence of human activities on landslides, mudflows and slope movements in India and efforts at reducing their negative impact. In Landslides and mudflows-reports of the Alma-Ata International Seminar 00:20-44

Matlab 9.0 (2016) The MathWorks Inc., Natick, Massachusetts

Mauldon M, Ureta J (1996) Stability analysis of rock wedges with multiple sliding surfaces. Geotechnical \& Geological Engineering 14(1):51-66

Most T, Knabe T (2010) Reliability analysis of the bearing failure problem considering uncertain stochastic parameters. Computers and Geotechnics 37(3):299-310

Pain A (2012) Rock slope stability assessment using rock mass characterization and discontinuity modelling. Masters Dissertation, AcSIR-Central Building Research Institute, Roorkee, India

Pandit B, Tiwari G, Latha GM, Babu GS (2018) Stability analysis of a large gold mine open-pit slope using advanced probabilistic method. Rock Mechanics and Rock Engineering 51(7):2153-2174

Pandit B, Tiwari G, Latha GM, Babu GS (2019) Probabilistic Characterization of Rock Mass from Limited Laboratory Tests and Field Data: Associated Reliability Analysis and Its Interpretation. Rock Mechanics and Rock Engineering 00:1-7

Rackwitz R, Flessler B (1978)Structural reliability under combined random load sequences. Computers and Structures 9(5):489-494 
604

605

606

607

608

609

610

611

612

613

614

615

616

617

618

619

620

621
Ramamurthy T (2014) Engineering in rocks for slopes, foundations and tunnels. Prentice Hall of India, New Delhi

Sarkar S, Kanungo DP, Patra AK (2005) Landslides in the Alaknanda Valley of Garhwal Himalaya, India. Quarterly Journal of Engineering Geology and Hydrogeology 39:79-42

Sarkar S, Pandit K, Shamra M, Pippal A (2018) Risk assessment and stability analysis of a recent landslide at Vishnuprayag on the Rishikesh-Badrinath highway, Uttarakhand, India Current Science 114 (7):1527-1533

Shukla DP, Dubey CS, Ningreichon AS, Singh RP, Mishra BK, Singh SK (2014) GIS based morpho-tectonic studies of Alaknanda River Basin: a precursor for hazard zonation. Natural Hazards 20:1433-1452

Tiwari G, Latha GM (2017) Reliability analysis of jointed rock slope considering uncertainty in peak and residual strength parameters. Bulletin of Engineering Geology and the Environment 78(2):913-930

Tiwari G, Latha GM (2019) Stability analysis and design of stabilization measures for Chenab railway bridge rock slopes. Bulletin of Engineering Geology and the Environment 79(2):603627

Wyllie DC, Mah C (2004) Rock slope engineering. Spon Press, New York 


\begin{tabular}{|c|c|}
\hline Table No & Caption \\
\hline Table 1 & Geometrical dimensions of the potential Rock-Slide 1 \\
\hline Table 2 & $\begin{array}{l}\text { Original data set for } \mathrm{JRC}_{\mathrm{n}}, \mathrm{JCS}_{\mathrm{n}} \text { and } \phi_{\mathrm{r}} \text { estimated for critical discontinuity } \\
\text { of potential Rock Slide } 1\end{array}$ \\
\hline Table 3 & $\begin{array}{l}\text { Statistical parameters and best-fit probability distributions of critical } \\
\text { discontinuity properties along with some external forces for potential Rock } \\
\text { Slide } 1\end{array}$ \\
\hline Table 4 & $\begin{array}{l}\text { Bootstrap mean and Bootstrap SD of sample mean and sample SD of JCS } \\
\mathrm{JRC}_{\mathrm{n}} \text { and } \phi_{\mathrm{r}} \text { for critical discontinuity of potential Rock Slide } 1\end{array}$ \\
\hline Table 5 & $\begin{array}{l}\text { Bootstrap mean and Bootstrap SD of } \mathrm{AIC}_{\mathrm{D}} \text { values for different probability } \\
\text { distributions for } \mathrm{JCS}_{\mathrm{n}}, \mathrm{JRC}_{\mathrm{n}} \text { and } \phi_{\mathrm{r}} \text { of critical discontinuity of potential } \\
\text { Rock Slide } 1\end{array}$ \\
\hline Table 6 & $\begin{array}{l}\text { Number of times a probability distribution is chosen as best-fit distribution } \\
\text { for } \mathrm{JCS}_{\mathrm{n}}, \mathrm{JRC}_{\mathrm{n}} \text { and } \phi_{\mathrm{r}} \text { of critical discontinuity during bootstrap sampling } \\
\text { for potential Rock Slide } 1\end{array}$ \\
\hline Table 7 & $\begin{array}{l}\text { Results of ARRA for potential Rock Slide } 1 \text { under in-situ and reinforced } \\
\text { condition }\end{array}$ \\
\hline Table 8 & $\begin{array}{l}\text { Details of TRA iterative scheme of MPTP search to achieve } \beta=2 \text { for } \\
\text { potential Rock Slide } 1\end{array}$ \\
\hline Table 9 & Geometrical dimensions of the potential Rock-Slide 2 \\
\hline Table 10 & $\begin{array}{l}\text { Original data set for } \mathrm{JRC}_{\mathrm{n}}, \mathrm{JCS}_{\mathrm{n}} \text { and } \phi_{\mathrm{r}} \text { estimated for both critical } \\
\text { discontinuities of potential Rock Slide } 2\end{array}$ \\
\hline Table 11 & $\begin{array}{l}\text { Statistical parameters and best-fit probability distributions of critical } \\
\text { discontinuities properties for potential Rock Slide } 2\end{array}$ \\
\hline Table 12 & $\begin{array}{l}\text { Results of ARRA for potential Rock Slide } 2 \text { under in-situ and reinforced } \\
\text { condition }\end{array}$ \\
\hline
\end{tabular}




\begin{tabular}{|c|c|}
\hline Figure No & Caption \\
\hline Fig. 1 & Illustration of locating MPTP during TRA \\
\hline Fig. 2 & $\begin{array}{l}\text { Flowchart of the proposed methodology describing involved calculation } \\
\text { steps }\end{array}$ \\
\hline Fig. 3 & Location of the potential rock slides \\
\hline Fig. 4 & $\begin{array}{l}\text { Pictures of the recent rock slide }\left(29^{\text {th }} \text { April, 2015) nearby to the studied }\right. \\
\text { locations (Sarkar et al., 2018) (a) Crushed boulders and fragments of a big } \\
\text { rock block blocking the highway (b) Crushed boulders and fragments } \\
\text { inside the Alaknanda River (c) Possible mode of rock slide is Planar along } \\
\text { an outwardly dipping joint }\end{array}$ \\
\hline Fig. 5 & $\begin{array}{l}\text { Details of the geometry and forces acting on the potential rock slide } 1 \\
\text { undergoing planar failure mode }\end{array}$ \\
\hline Fig. 6 & $\begin{array}{l}\text { Probability distributions of the (a) sample mean of } \phi_{\mathrm{r}} \text {, (b) sample SD of } \phi_{\mathrm{r}} \text {, } \\
\text { (c) sample mean of } \mathrm{JRC}_{\mathrm{n}},(\mathrm{d}) \text { sample SD of } \mathrm{JRC}_{\mathrm{n}} \text {, (e) sample mean of } \mathrm{JCS}_{\mathrm{n}} \\
\text { and (f) sample SD of } \mathrm{JCS}_{\mathrm{n}}\end{array}$ \\
\hline Fig. 7 & Probability distributions of $\mathrm{AIC}_{\mathrm{D}}$ for (a) $\phi_{\mathrm{r}}$, (b) $\mathrm{JRC}_{\mathrm{n}}$ and (c) $\mathrm{JCS}_{\mathrm{n}}$ \\
\hline Fig. 8 & $\begin{array}{l}\text { Probability distribution of FOSevaluated using traditional reliability } \\
\text { analysis for potential Rock Slide } 1\end{array}$ \\
\hline Fig. 9 & $\begin{array}{l}\text { Probability distributions of (a) sample mean of FOS, (b) sample SD of FOS } \\
\text { and(c) reliability index evaluated by ARRA for potential Rock Slide } 1\end{array}$ \\
\hline Fig. 10 & $\begin{array}{l}\text { Probability distribution of the reliability index evaluated from ARRA for } \\
\text { potential rock slide } 1 \text { under different conditions }\end{array}$ \\
\hline Fig. 11 & Details of the remedial measures suggested to mitigate rock slide 1 \\
\hline Fig. 12 & $\begin{array}{l}\text { Details of the geometry and forces acting on the potential rock slide } 2 \\
\text { undergoing wedge failure mode }\end{array}$ \\
\hline Fig. 13 & $\begin{array}{l}\text { Probability distributions of the (a) sample mean of } \phi_{\mathrm{r} 1} \text {, (b) sample SD of } \\
\phi_{\mathrm{r} 1} \text {, (c) sample mean of } \phi_{\mathrm{r} 2} \text {, (d) sample SD of } \phi_{\mathrm{r} 2} \text {, (e) AIC } \mathrm{C}_{\mathrm{D}} \text { for } \phi_{\mathrm{r} 1} \text { and (f) } \\
\mathrm{AIC}_{\mathrm{D}} \text { for } \phi_{\mathrm{r} 2} \text { (only the variation in statistical parameters of } \phi_{\mathrm{r}} \text { for both } \\
\text { discontinuity planes are shown) }\end{array}$ \\
\hline Fig. 14 & $\begin{array}{l}\text { Probability distribution of the reliability index evaluated from ARRA for } \\
\text { potential rock slide } 2 \text { under different conditions }\end{array}$ \\
\hline Fig. 15 & Details of the remedial measures suggested to mitigate rock slide 2 \\
\hline
\end{tabular}



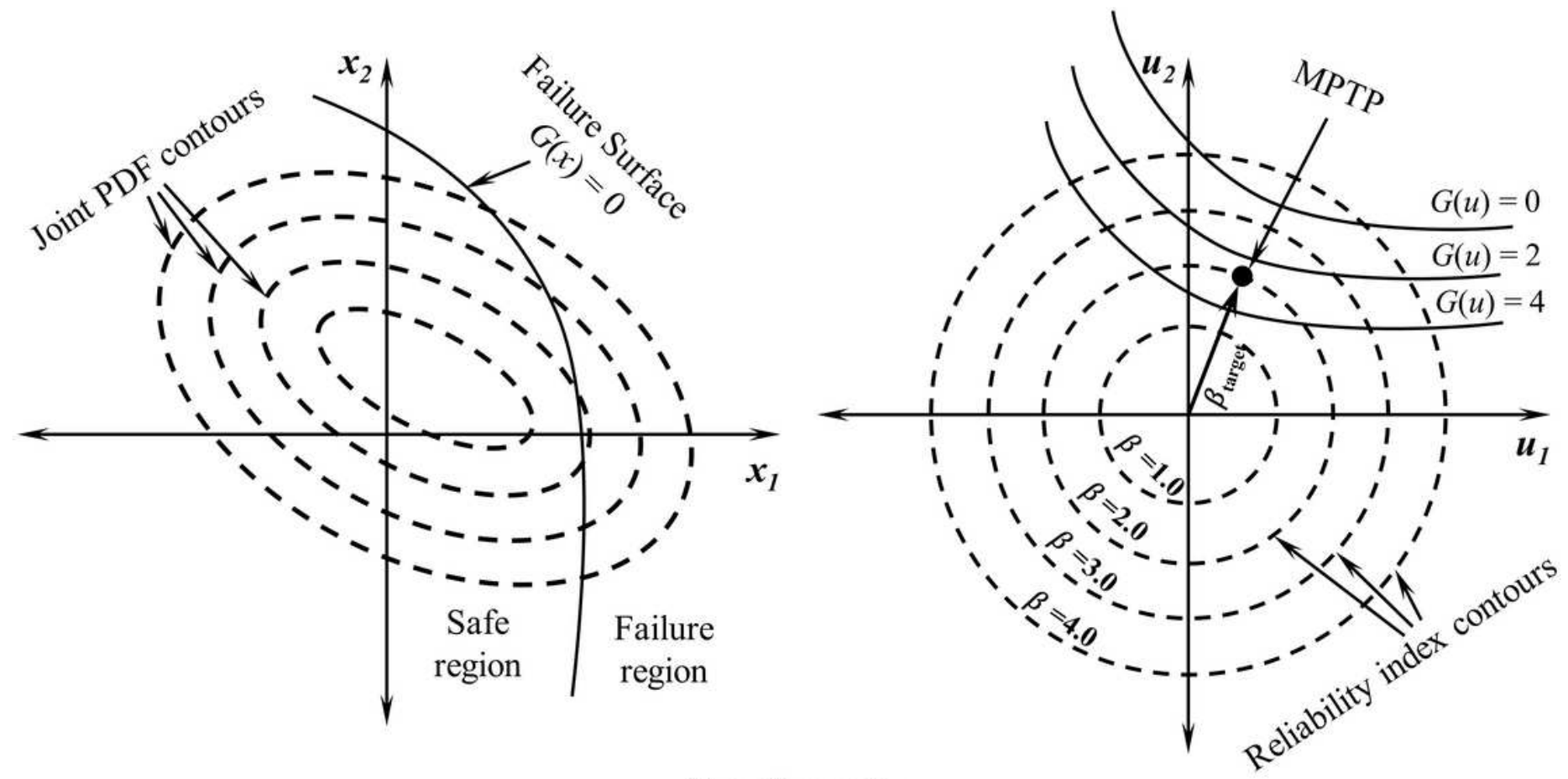

Transformation

Random variable space (X-space)

Standard normal space (U-space)

Figure 1

Illustration of locating MPTP during TRA 


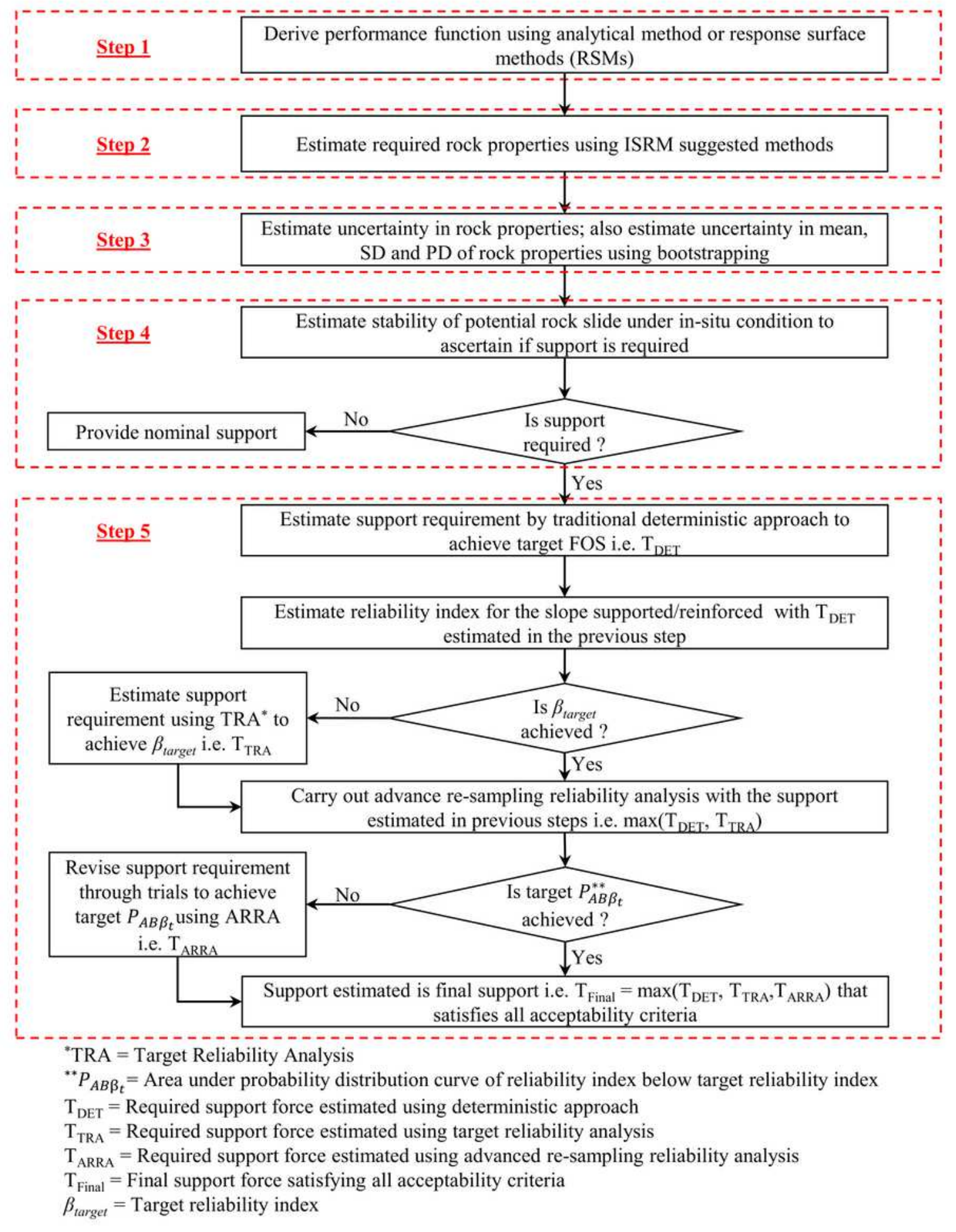

\section{Figure 2}



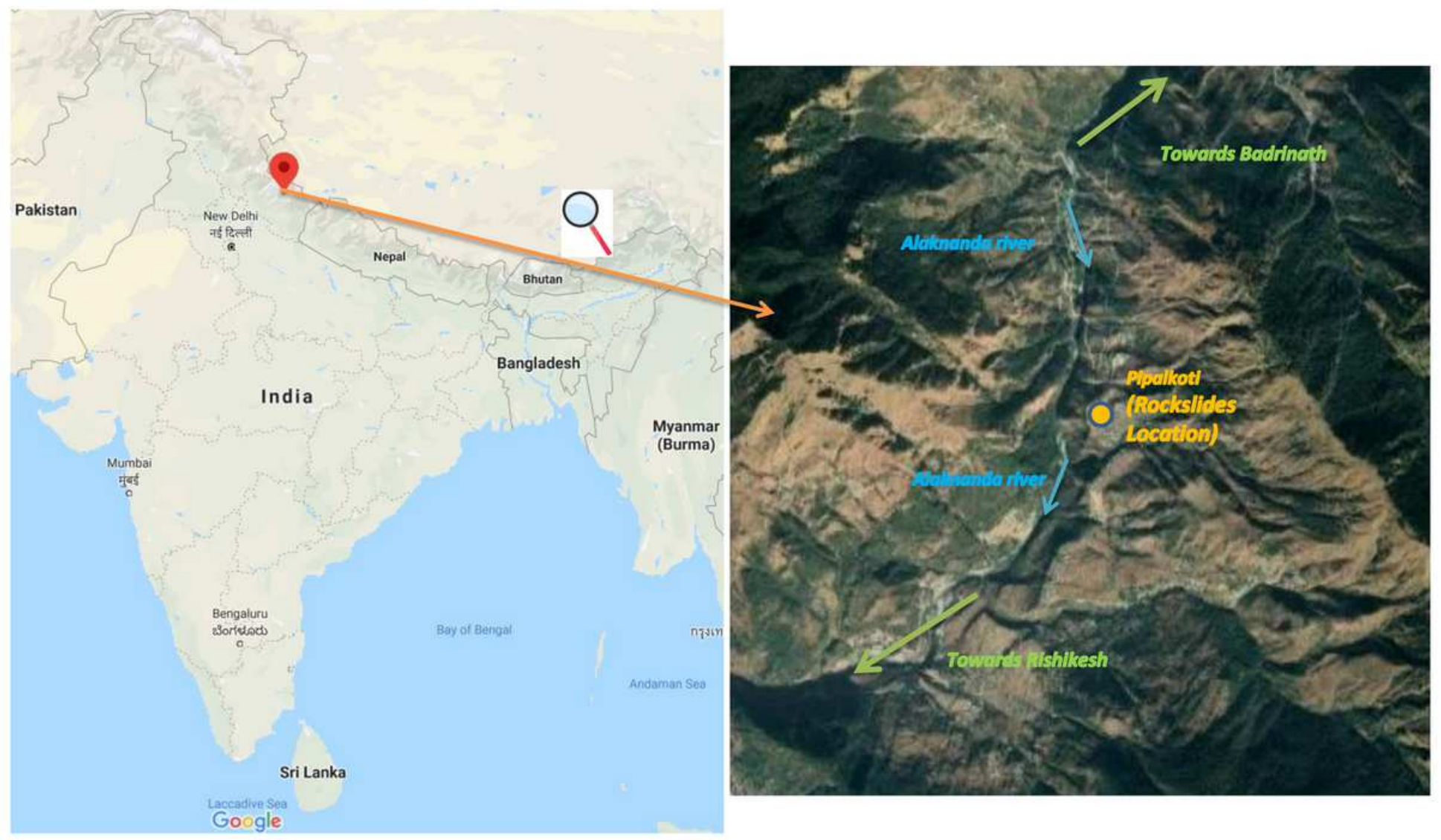

\section{Figure 3}

Location of the potential rock slides Note: The designations employed and the presentation of the material on this map do not imply the expression of any opinion whatsoever on the part of Research Square concerning the legal status of any country, territory, city or area or of its authorities, or concerning the delimitation of its frontiers or boundaries. This map has been provided by the authors. 
(a)

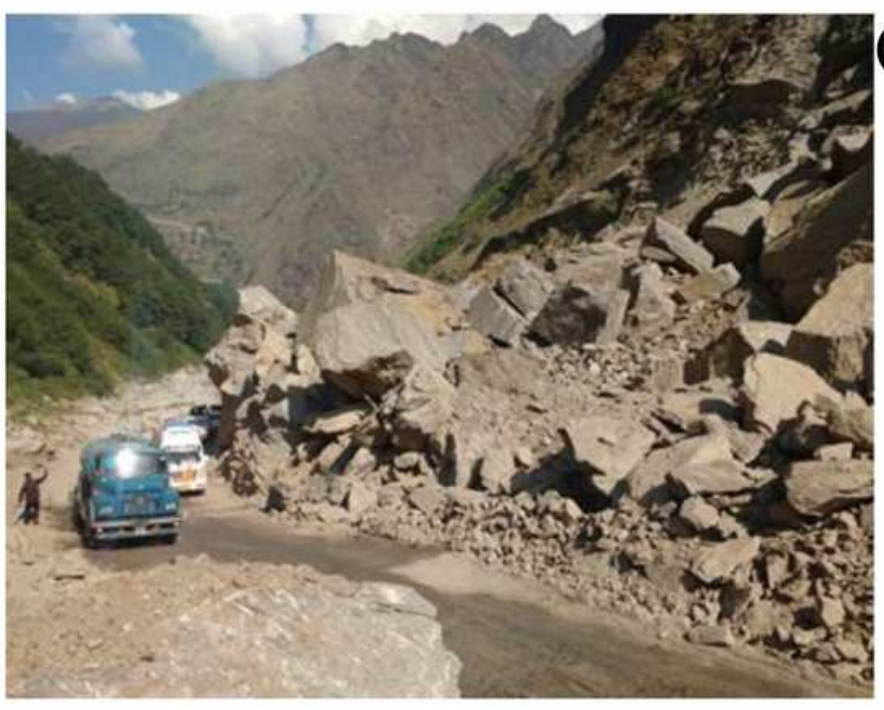

(b)

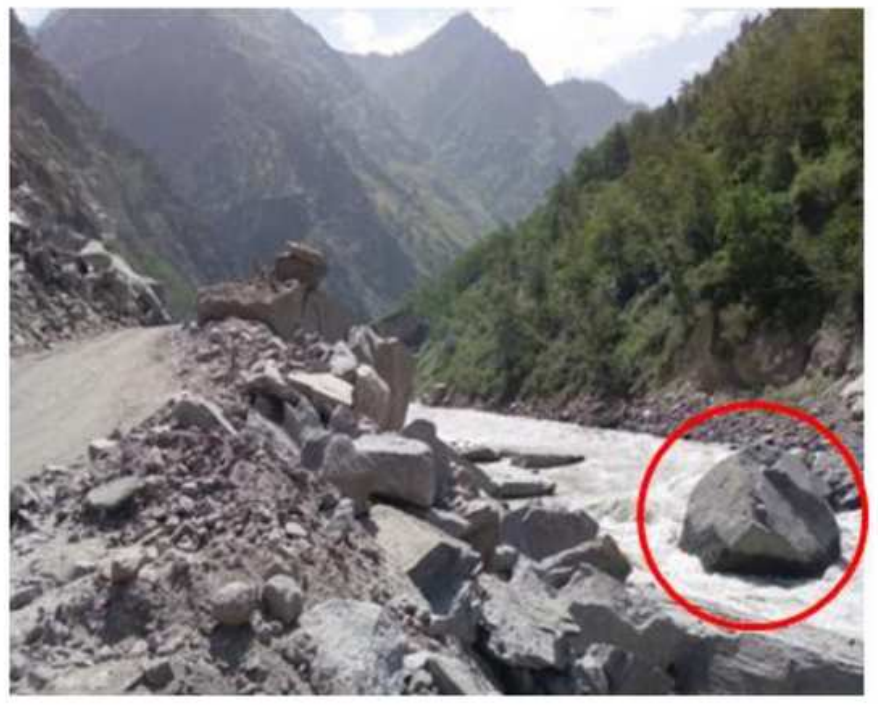

(c)

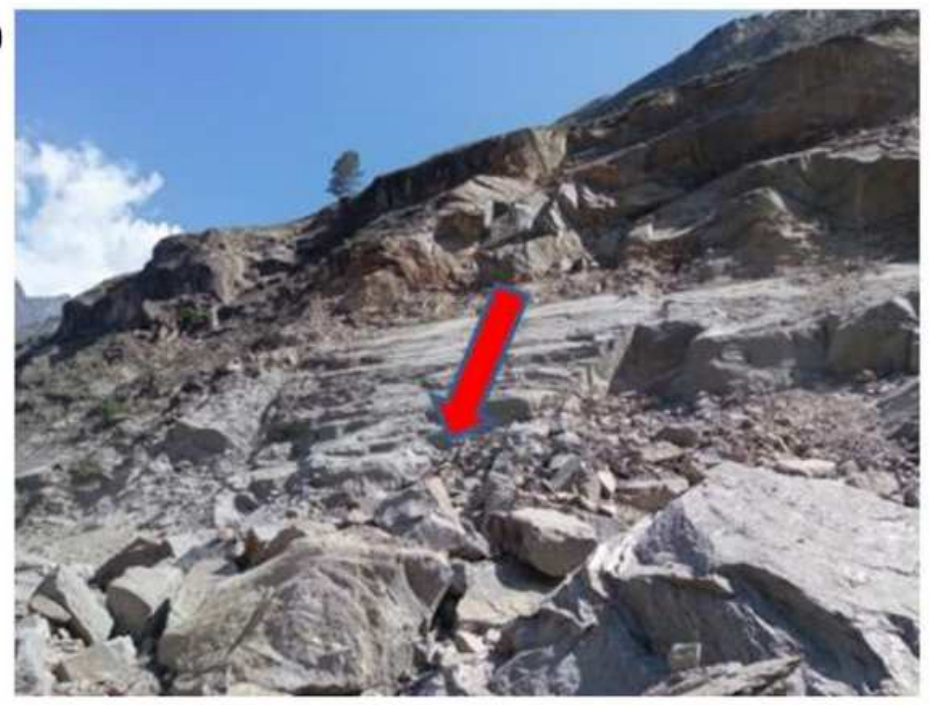

Figure 4

Pictures of the recent rock slide (29th April, 2015) nearby to the studied locations (Sarkar et al., 2018) (a) Crushed boulders and fragments of a big rock block blocking the highway (b) Crushed boulders and fragments inside the Alaknanda River (c) Possible mode of rock slide is Planar along an outwardly dipping joint 


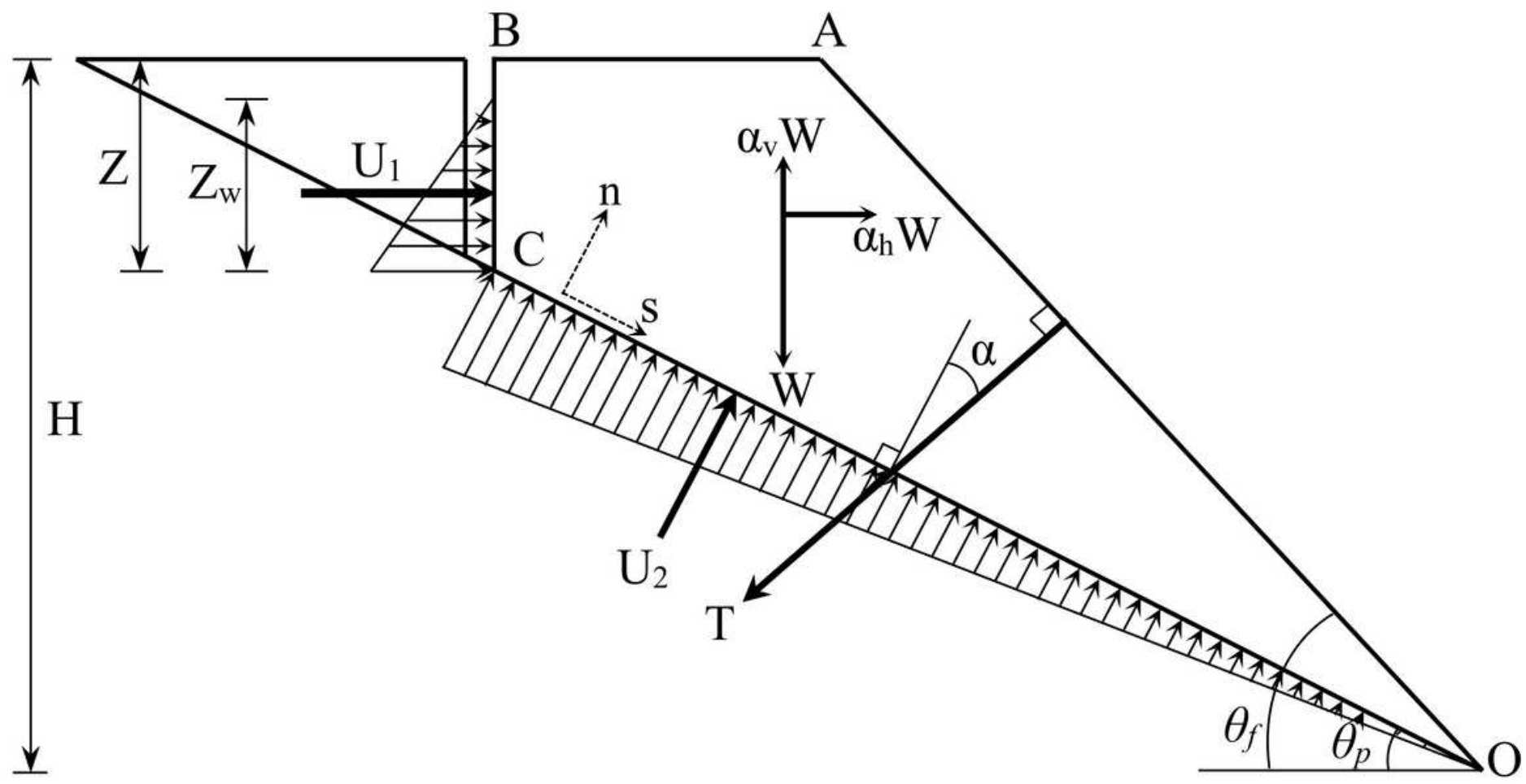

Figure 5

Details of the geometry and forces acting on the potential rock slide 1 undergoing planar failure mode 
(a)

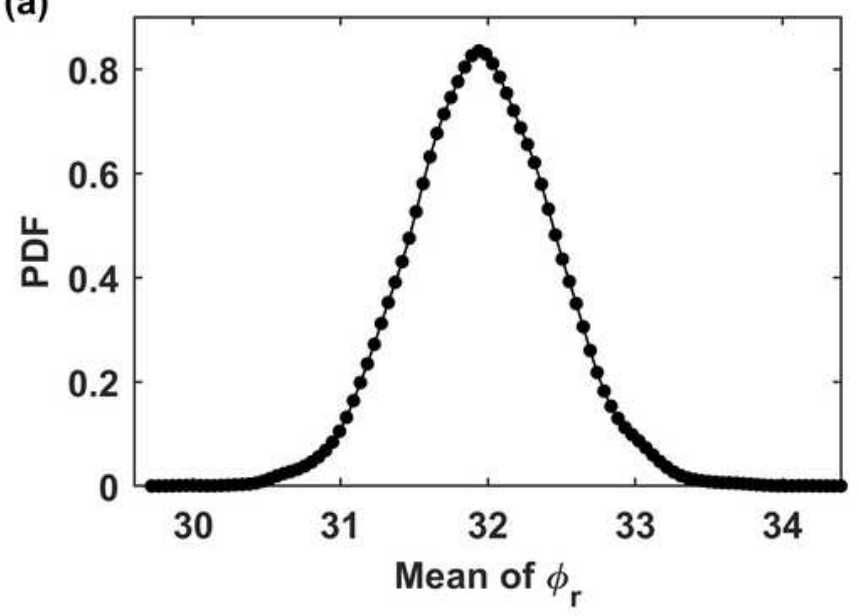

(c)

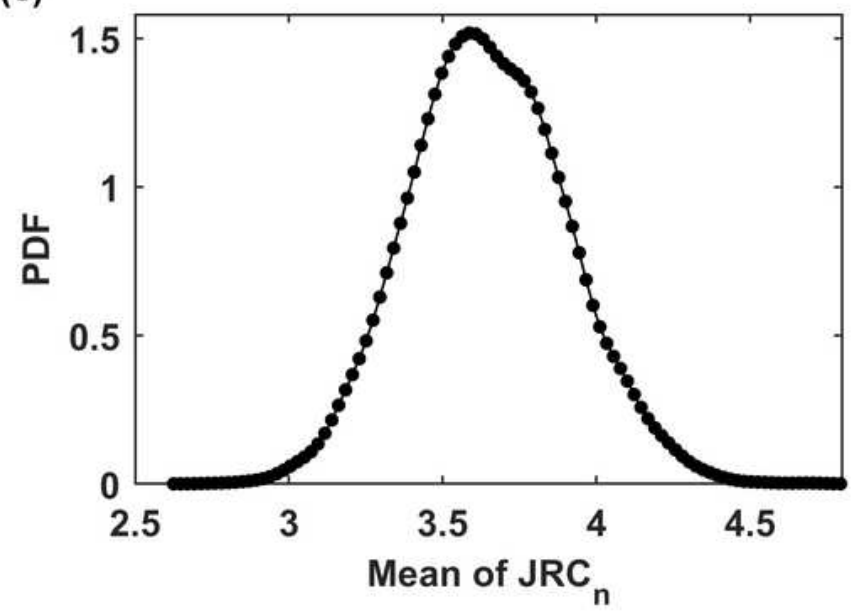

(e)

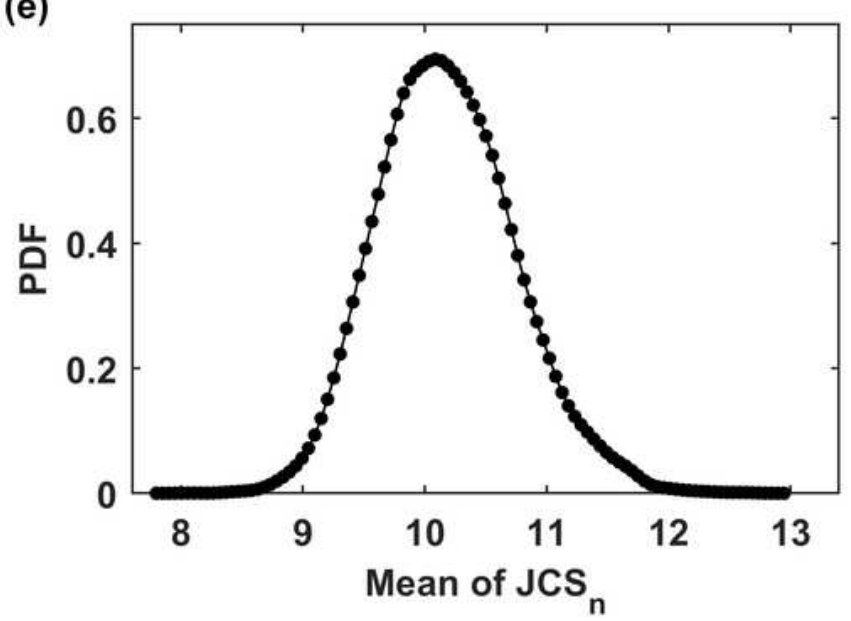

(b)

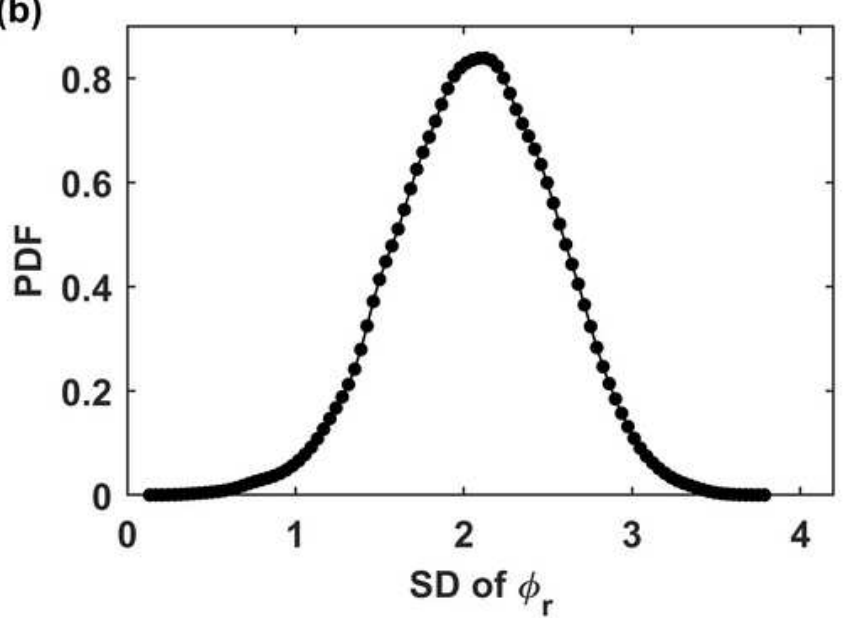

(d)

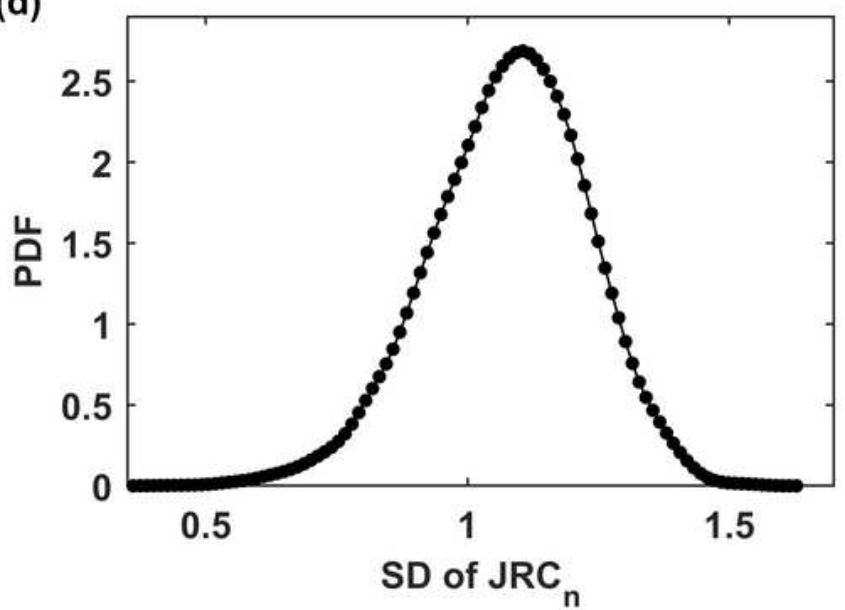

(f)

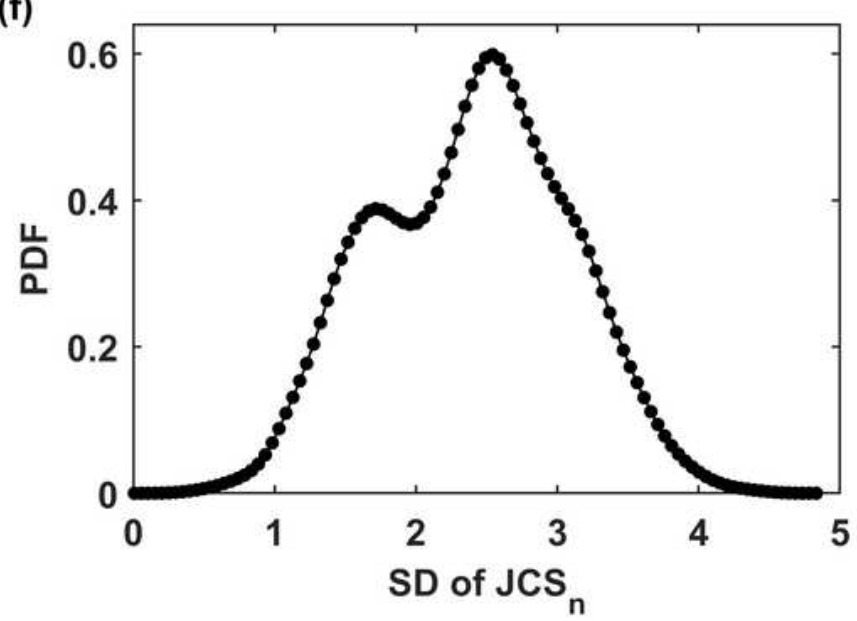

Figure 6

Probability distributions of the (a) sample mean of $₫ r$, (b) sample SD of $\varangle r$, (c) sample mean of JRCn, (d) sample SD of JRCn, (e) sample mean of JCSn and (f) sample SD of JCSn 
(a)

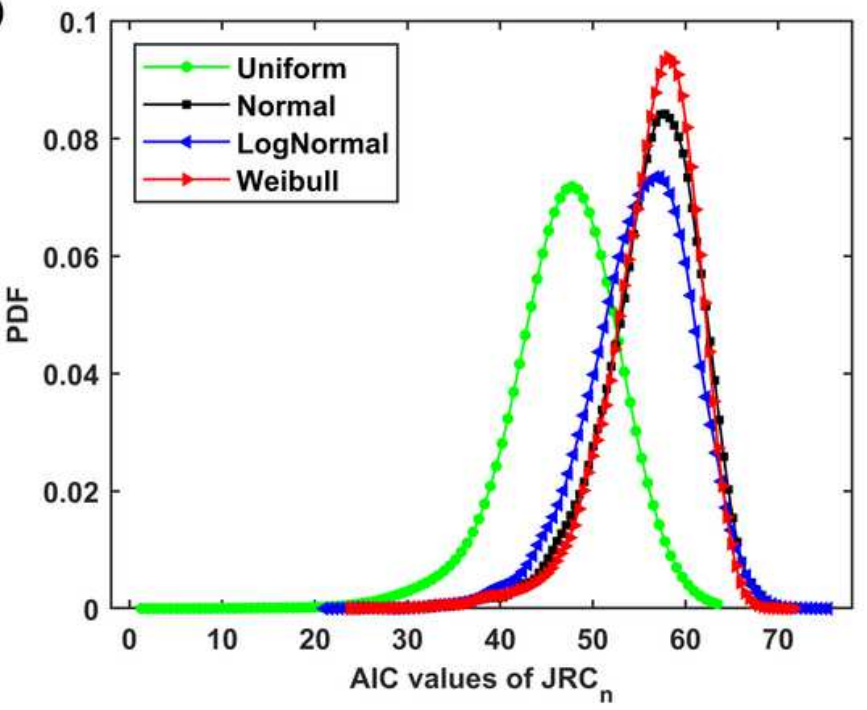

(b)

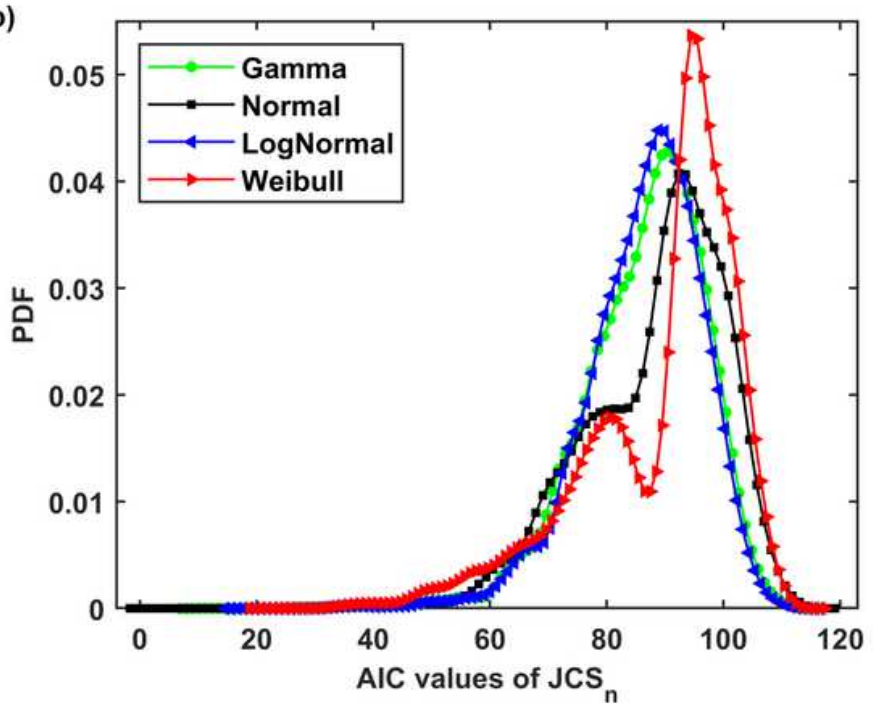

(c)

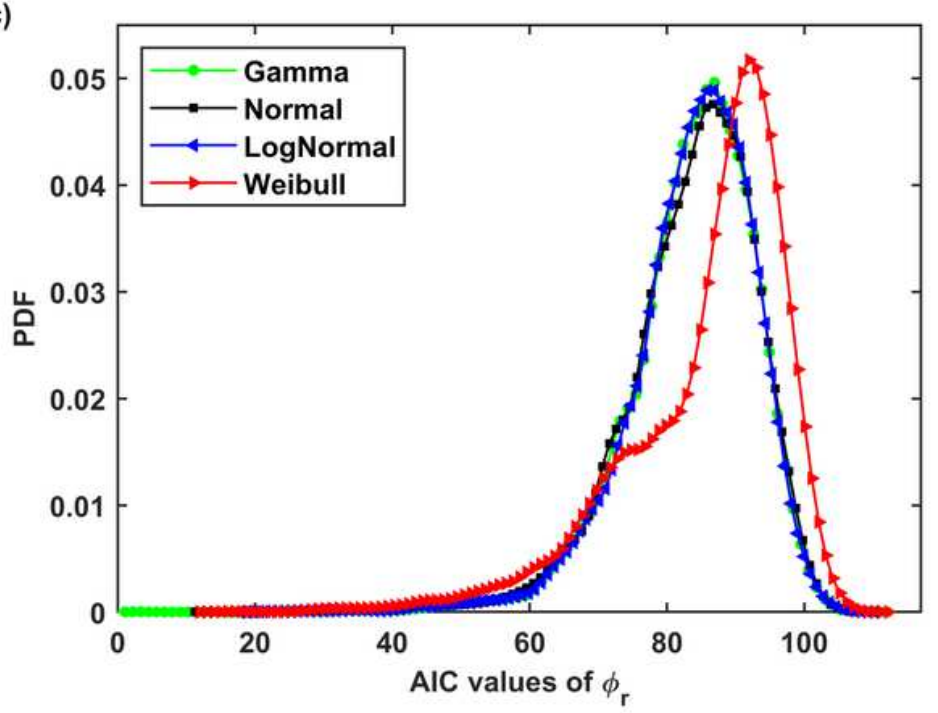

Figure 7

Probability distributions of AICD for (a) $\Downarrow r$, (b) JRCn and (c) JCSn 


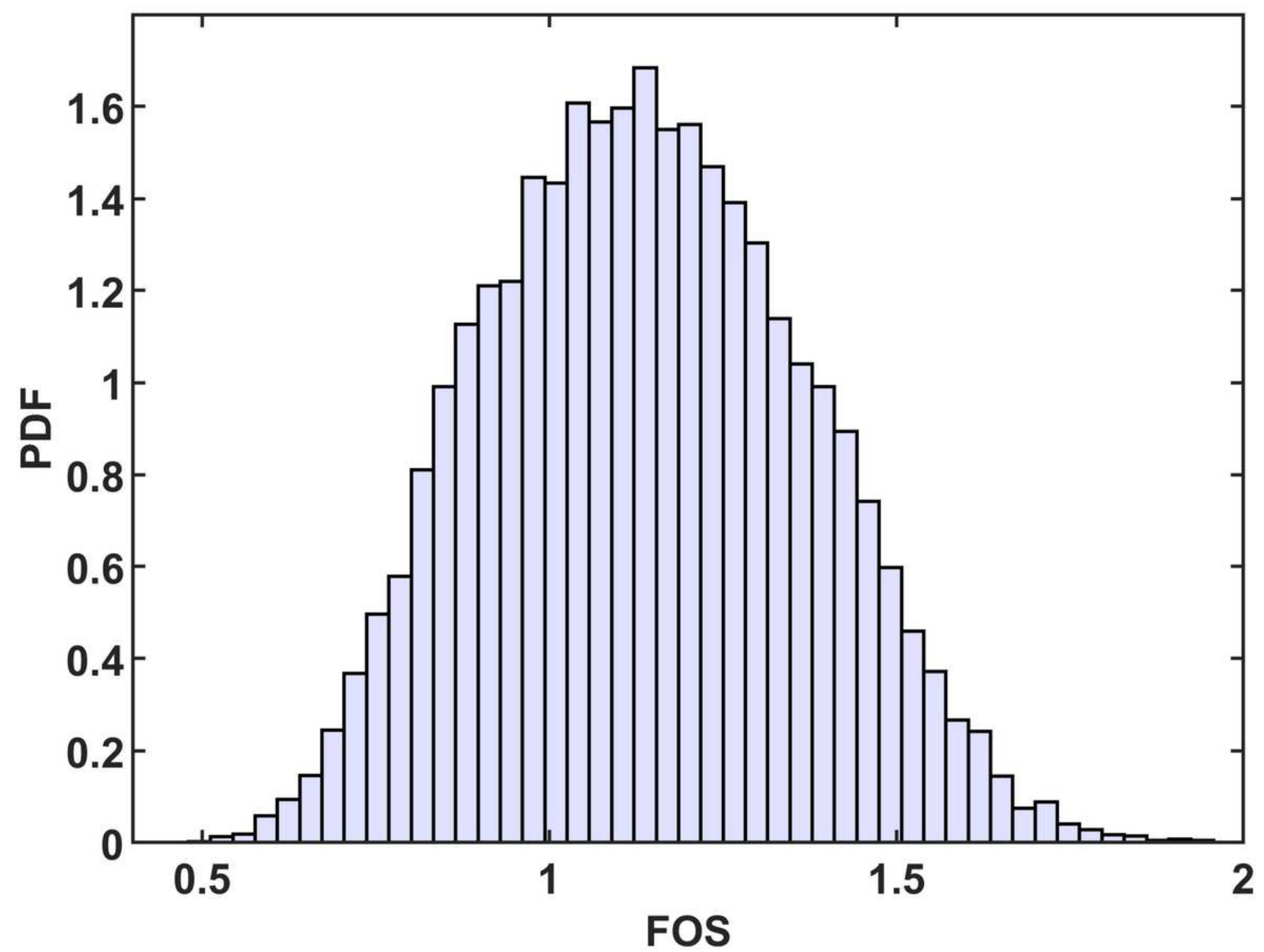

Figure 8

Probability distribution of FOSevaluated using traditional reliability analysis for potential Rock Slide 1 

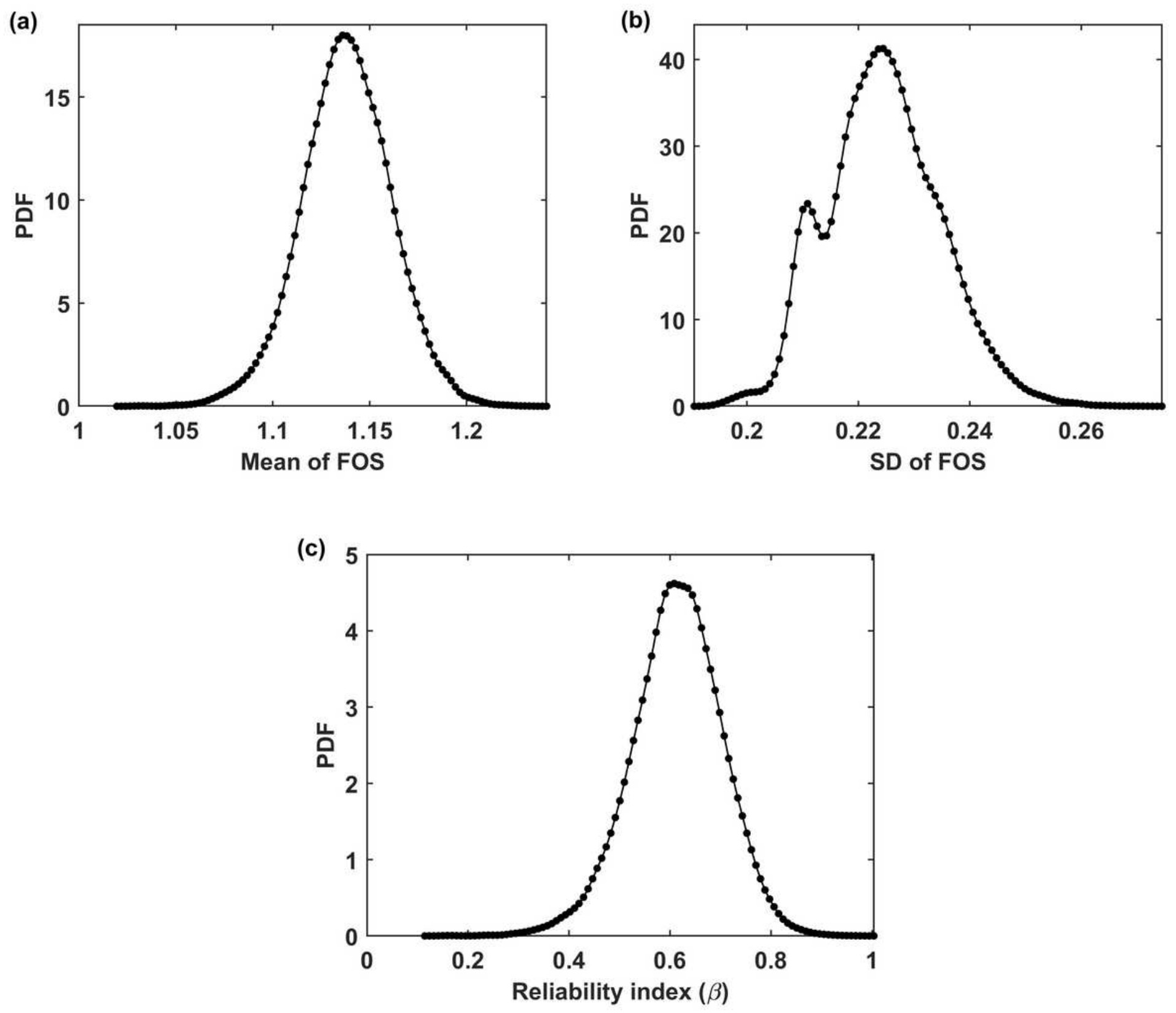

Figure 9

Probability distributions of (a) sample mean of FOS, (b) sample SD of FOS and(c) reliability index evaluated by ARRA for potential Rock Slide 1 


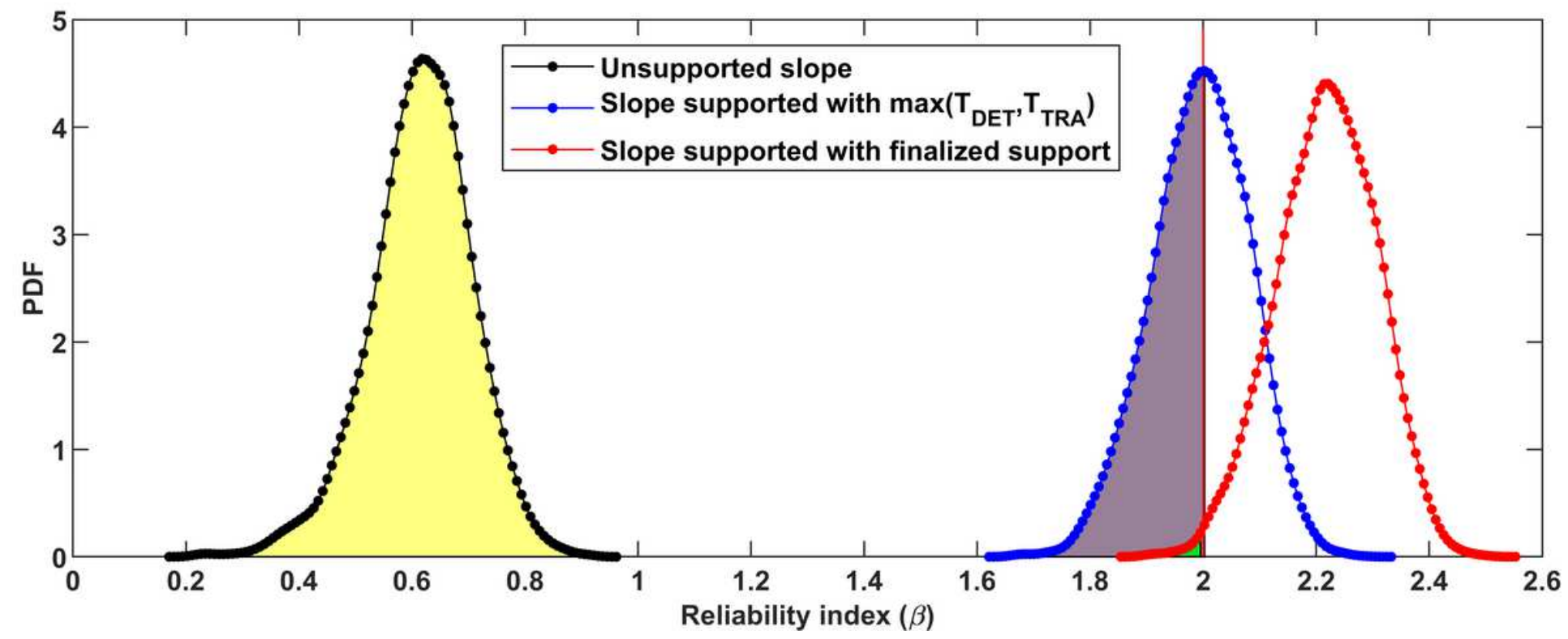

Figure 10

Probability distribution of the reliability index evaluated from ARRA for potential rock slide 1 under different conditions

$32 \mathrm{~mm}$ Rock Bolt of Tensile Capacity $100 \mathrm{kN}$ with $80 \%$ Pre-Tensioning

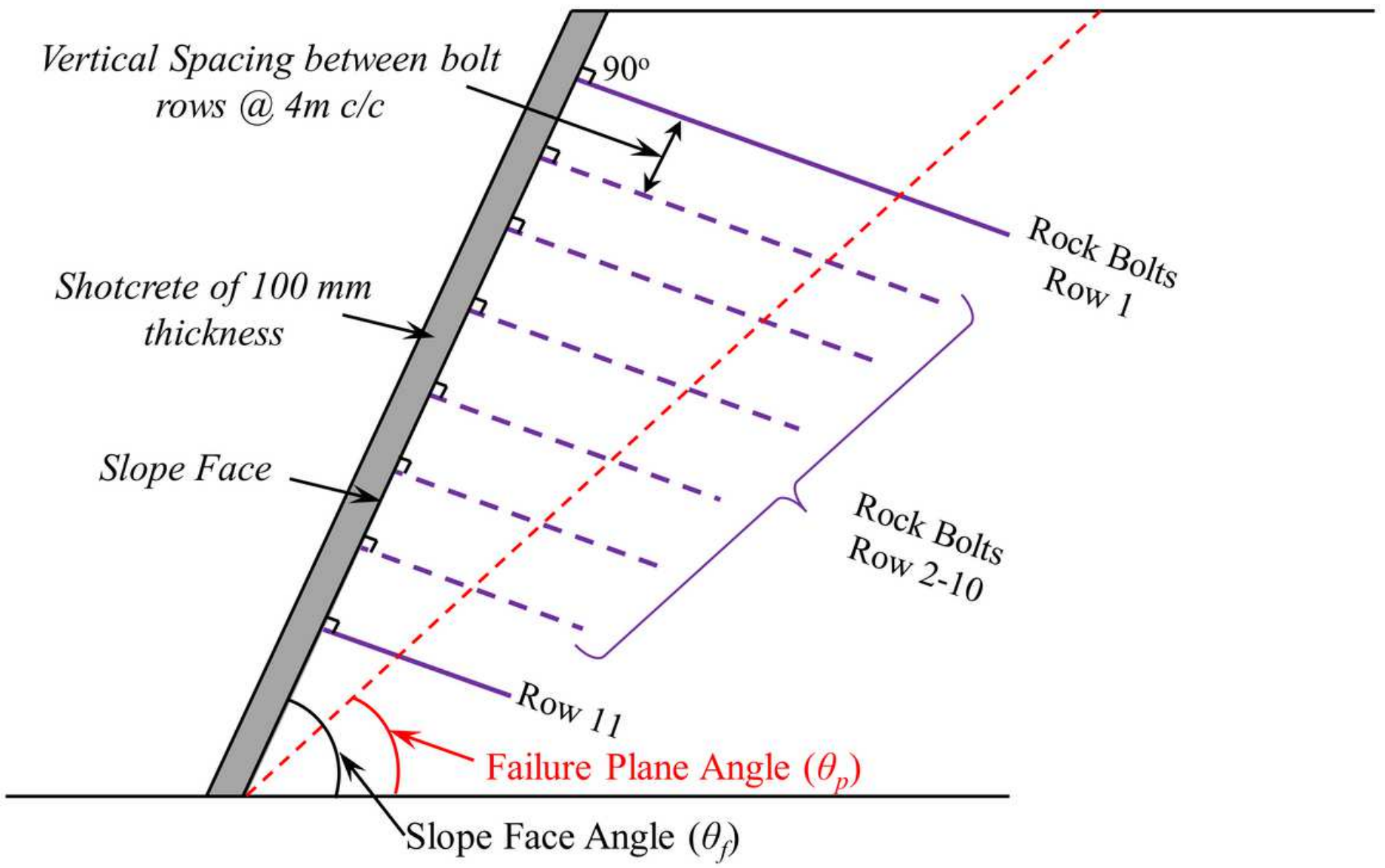


Figure 11

Details of the remedial measures suggested to mitigate rock slide 1

(a)

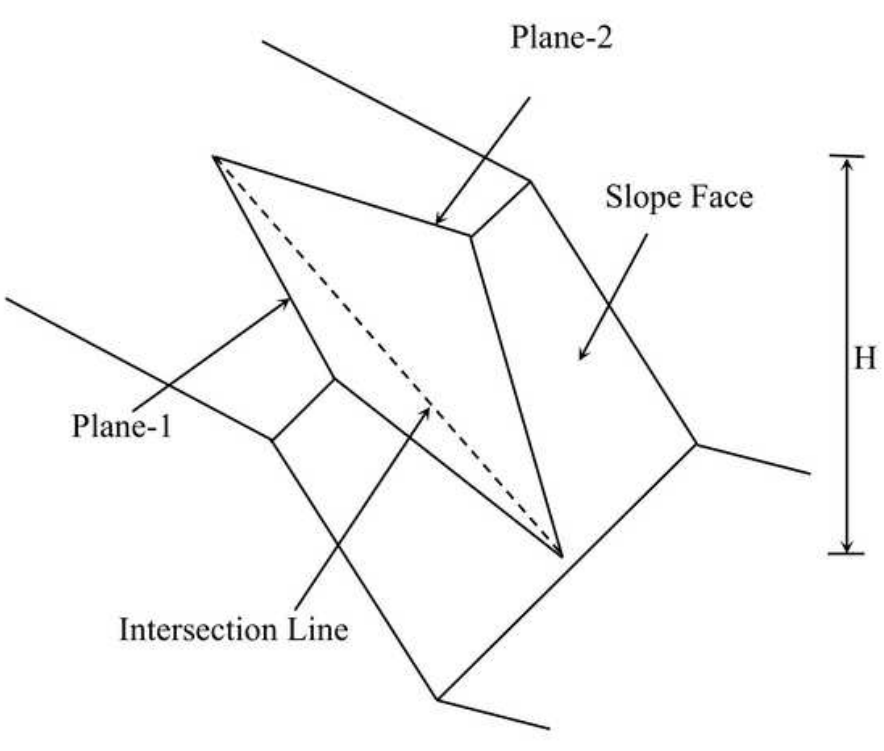

(b)

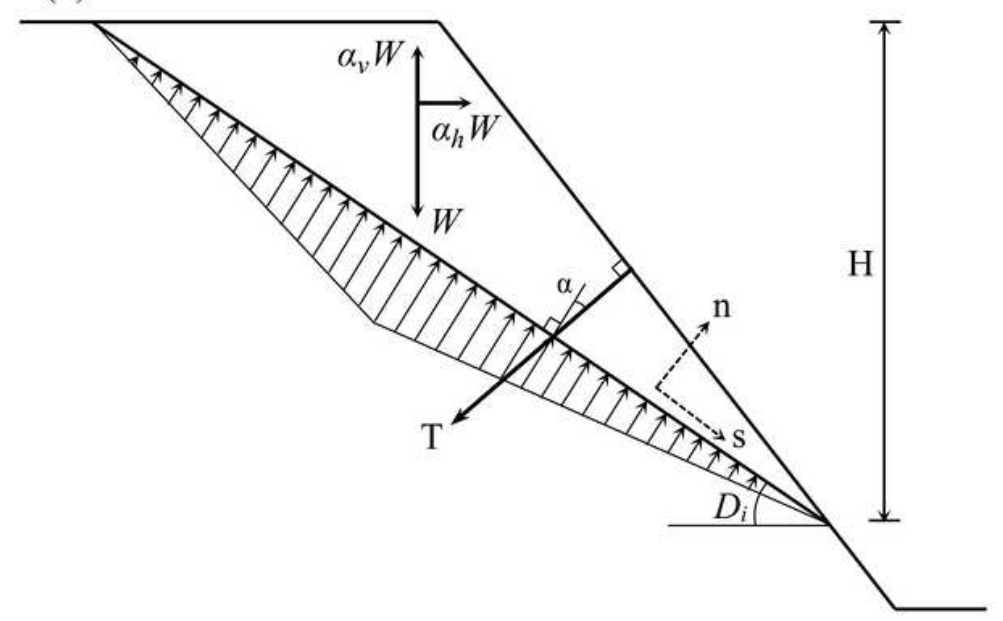

(c)

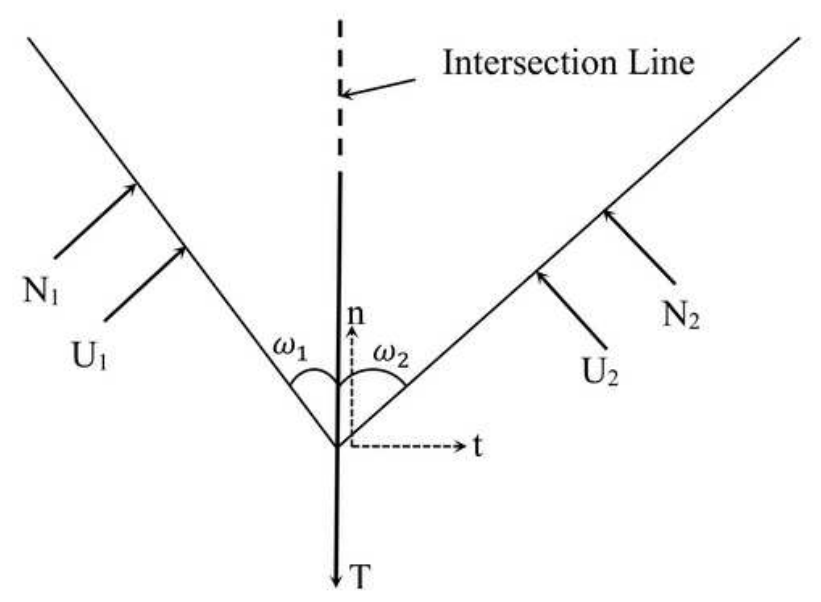

\section{Figure 12}

Details of the geometry and forces acting on the potential rock slide 2 undergoing wedge failure mode 
(a)
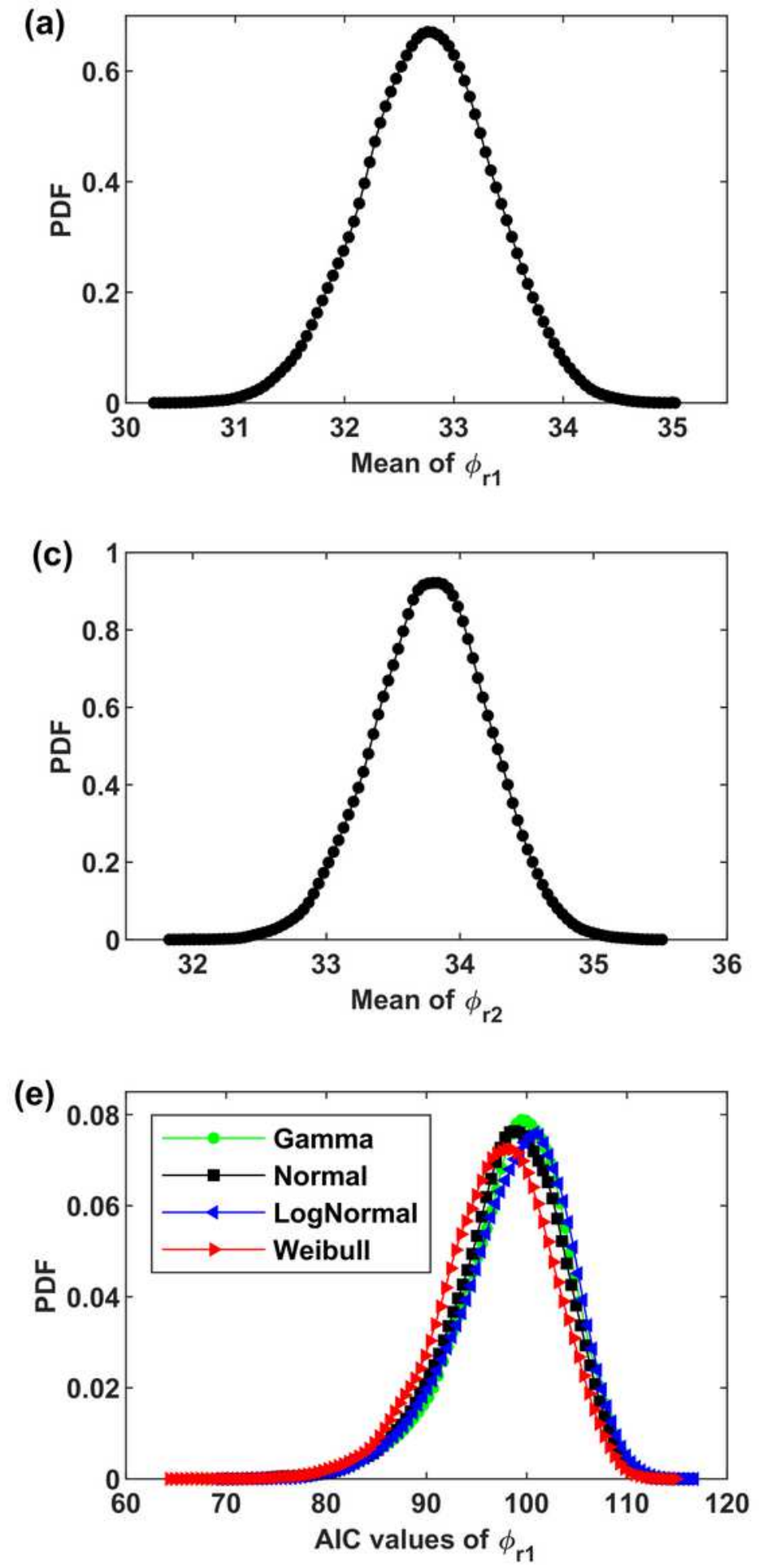
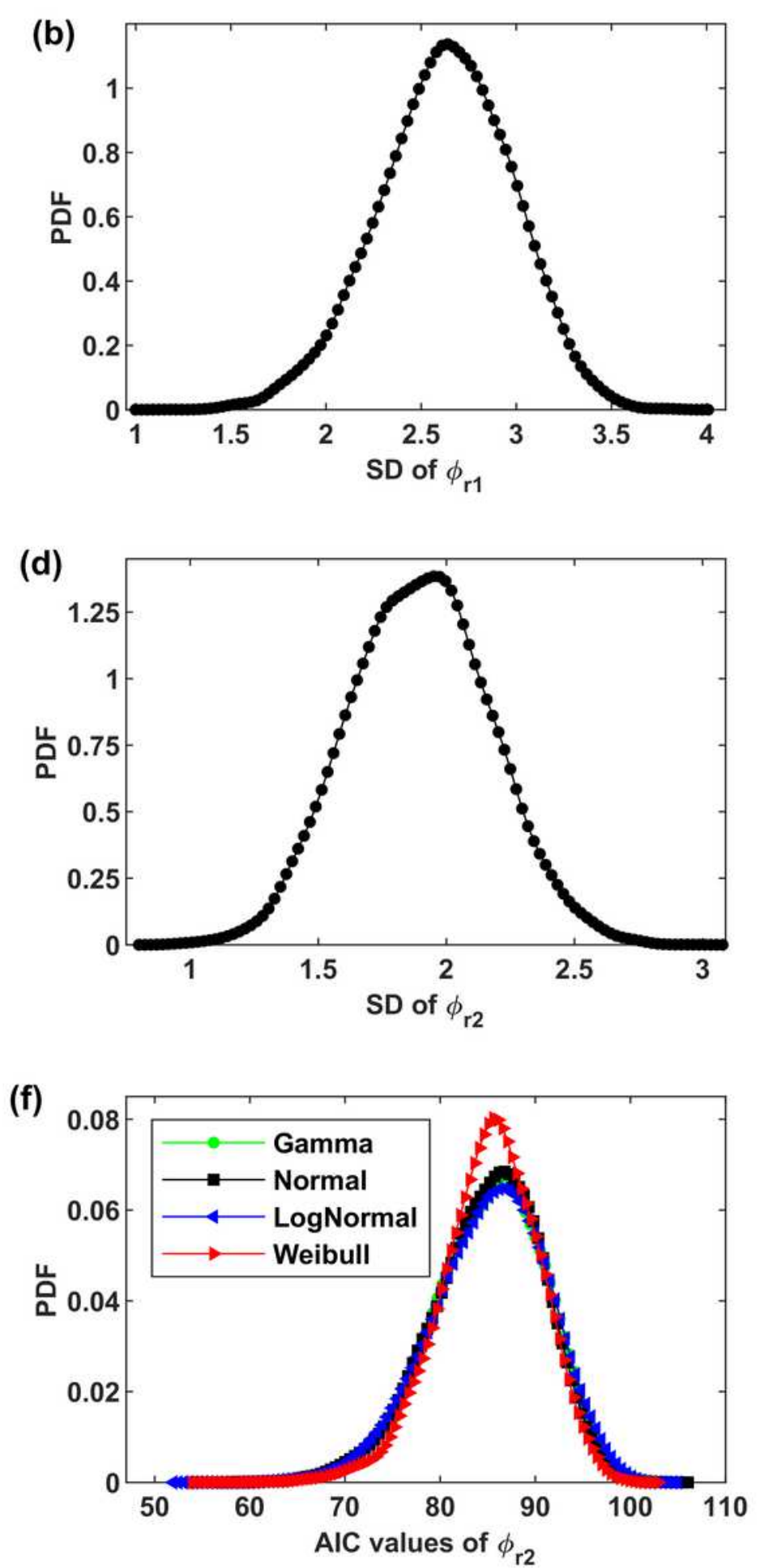

Figure 13

Probability distributions of the (a) sample mean of $₫ r 1$, (b) sample SD of $\nabla r 1$, (c) sample mean of $\nabla r 2$, (d)

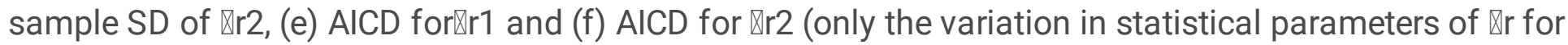
both discontinuity planes are shown) 


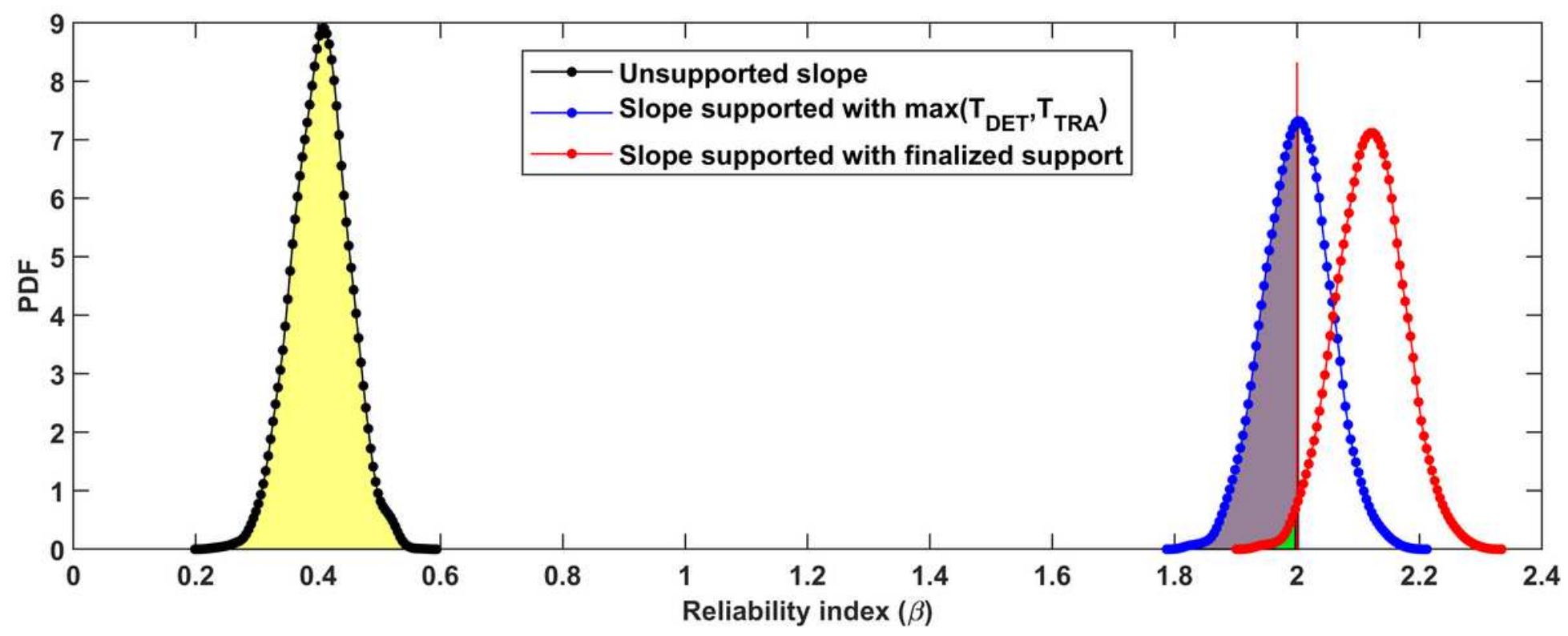

Figure 14

Probability distribution of the reliability index evaluated from ARRA for potential rock slide 2 under different conditions 


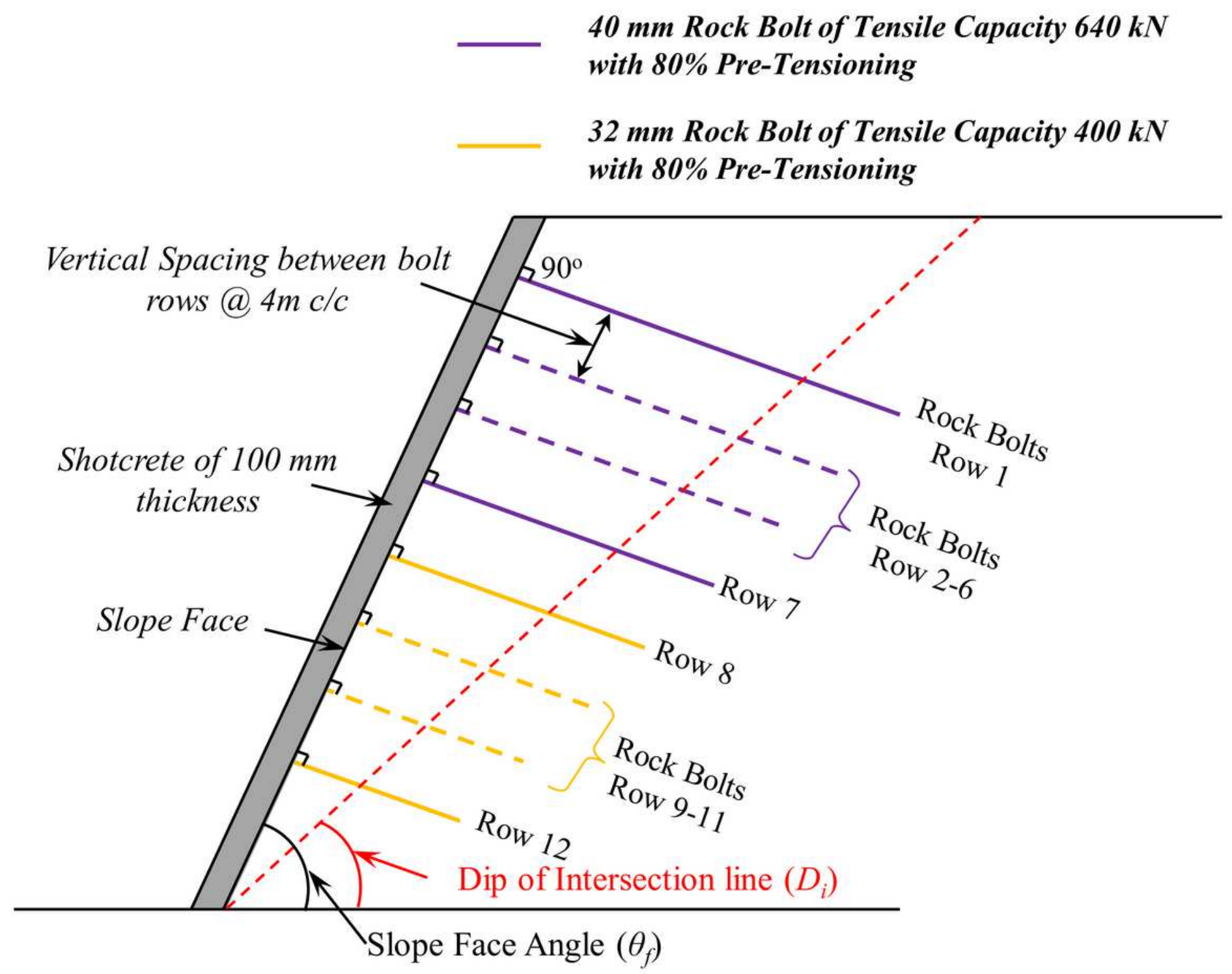

Figure 15

Details of the remedial measures suggested to mitigate rock slide 2 